\title{
Presynaptic dystrophic neurites surrounding amyloid plaques are sites of microtubule disruption, BACE1 elevation, and increased $\mathrm{A} \beta$ generation in Alzheimer's disease
}

\author{
Katherine R. Sadleir ${ }^{1} \cdot$ Patty C. Kandalepas ${ }^{1} \cdot$ Virginie Buggia-Prévot $^{2,4}$. \\ Daniel A. Nicholson ${ }^{3} \cdot$ Gopal Thinakaran $^{2} \cdot$ Robert Vassar $^{1}$
}

Received: 13 October 2015 / Revised: 27 February 2016 / Accepted: 2 March 2016 / Published online: 18 March 2016

(c) The Author(s) 2016. This article is published with open access at Springerlink.com

\begin{abstract}
Alzheimer's disease (AD) is characterized by amyloid plaques composed of the $\beta$-amyloid $(\mathrm{A} \beta)$ peptide surrounded by swollen presynaptic dystrophic neurites consisting of dysfunctional axons and terminals that accumulate the $\beta$-site amyloid precursor protein (APP) cleaving enzyme (BACE1) required for $A \beta$ generation. The cellular and molecular mechanisms that govern presynaptic dystrophic neurite formation are unclear, and elucidating these processes may lead to novel AD therapeutic strategies. Previous studies suggest $A \beta$ may disrupt microtubules, which we hypothesize have a critical role in the development of presynaptic dystrophies. To investigate this further, here we have assessed the effects of $A \beta$, particularly neurotoxic $A \beta 42$, on microtubules during the formation of presynaptic dystrophic neurites in vitro and in vivo. Live-cell imaging of primary neurons revealed that exposure to $A \beta 42$ oligomers caused varicose and beaded neurites with extensive
\end{abstract}

Electronic supplementary material The online version of this article (doi:10.1007/s00401-016-1558-9) contains supplementary material, which is available to authorized users.

Robert Vassar

r-vassar@northwestern.edu

1 Department of Cell and Molecular Biology, Feinberg School of Medicine, Northwestern University, Chicago, IL 60611, USA

2 Departments of Neurobiology, Neurology and Pathology, The University of Chicago, Chicago, IL 60637, USA

3 Department of Neurological Sciences, Rush University, Chicago, IL 60612, USA

4 Present Address: The Neurodegeneration Consortium, Institute for Applied Cancer Science (IACS), The University of Texas MD Anderson Cancer Center, Houston, TX 77054, USA microtubule disruption, and inhibited anterograde and retrograde trafficking. In brain sections from $\mathrm{AD}$ patients and the 5XFAD transgenic mouse model of amyloid pathology, dystrophic neurite halos with BACE1 elevation around amyloid plaques exhibited aberrant tubulin accumulations or voids. At the ultrastructural level, peri-plaque dystrophies were strikingly devoid of microtubules and replete with multilamellar vesicles resembling autophagic intermediates. Proteins of the microtubule motors, kinesin and dynein, and other neuronal proteins were aberrantly localized in periplaque dystrophies. Inactive pro-cathepsin $\mathrm{D}$ also accumulated in peri-plaque dystrophies, indicating reduced lysosomal function. Most importantly, BACE1 accumulation in peri-plaque dystrophies caused increased BACE1 cleavage of APP and $A \beta$ generation. Our study supports the hypothesis that $A \beta$ induces microtubule disruption in presynaptic dystrophic neurites that surround plaques, thus impairing axonal transport and leading to accumulation of BACE1 and exacerbation of amyloid pathology in AD.

Keywords Alzheimer's disease - Amyloid - A $\beta$ - BACE1 · Dystrophic neurite $\cdot$ Microtubule $\cdot$ Tubulin $\cdot$ Axonal transport $\cdot$ Cathepsin D . 5XFAD mice

\section{Introduction}

The $\beta$-amyloid (A $\beta$ ) peptide, the major component of amyloid plaques, has a crucial early role in Alzheimer's disease (AD) pathogenesis [58]. The membrane aspartic protease $\beta$-site amyloid precursor protein (APP) cleaving enzyme 1 (BACE1) is the major $\beta$-secretase enzyme that initiates the production of A $\beta$ from APP $[20,54,66$, 79]. Mutations in APP at the BACE1 cleavage site cause (K670N/M671L [38], A673V [8]) or prevent (A673T 
[24]) AD by increasing or decreasing BACE1 cleavage of $\mathrm{APP}$ and $\mathrm{A} \beta$ production, respectively. Also, a mutation at the $\beta^{\prime}$-site (E682K [87]) causes AD by shifting BACE1 cleavage toward $\beta$-site processing of APP and A $\beta$ generation. These mutations and other evidence strongly support therapeutic BACE1 inhibition for AD [67]. BACE1 inhibitor drugs are in clinical trials; however, the safety and efficacy of these drugs are unknown. BACE1 null mice have multiple neurological phenotypes indicating BACE1 inhibitor drugs could have mechanism-based toxicities [67]. BACE1 levels are elevated in AD brain [14, $18,31,80,86]$ potentially necessitating high doses of BACE1 inhibitor drugs, thus increasing the risk of side effects. Lowering/normalizing BACE1 levels in AD brain rather than direct inhibition of enzyme activity offers an alternative therapeutic approach that could avoid BACE1 inhibitor side effects. Elucidating the mechanism of BACE1 elevation in AD is essential for developing BACE1 lowering strategies.

While the mechanism of BACE1 elevation in brains of $\mathrm{AD}$ patients or mouse models of $\mathrm{AD}$ is not yet clear, recent data indicate that BACE1 levels are upregulated during stresses associated with $\mathrm{AD}$ risk, such as energy deprivation [39, 68], hypoxia and stroke [56, 71, 84], oxidative stress [61], and traumatic brain injury [2, 65]. A large number of molecular pathways have been proposed to increase BACE1 levels: increased caspase 3 activity leading to impaired lysosomal degradation [26, 60], Cdk5 phosphorylation of transcription factor Stat3 [72], altered microRNAs $[3,12,17,69,88]$, transcription factor HIF1 $\alpha$ activity, [84], elevated phosphorylation of the elongation initiation factor eIF2 $\alpha$ [39]. Thus, BACE1 appears to be a stress-response protein that can be regulated via diverse molecular pathways, making it challenging to identify the precise mechanism(s) involved in AD-relevant BACE1 elevation.

Insights into the mechanism of BACE1 elevation in $\mathrm{AD}$ have come from analysis of the localization pattern of increased BACE1 in the brains of AD patients and transgenic mouse models of amyloid pathology. Importantly, BACE1 elevation is not uniform throughout the brain, but is concentrated in presynaptic dystrophic neurites that surround amyloid plaques $[25,86]$ where it potentially spurs $\mathrm{A} \beta$ generation and plaque growth. Close proximity to plaques is associated with presynaptic dystrophy and $\mathrm{A} \beta 42$ oligomers increase BACE1 levels in cultured neurons [48, 49], thus implicating $A \beta$ neurotoxicity in these processes. Reticulon 3 is involved in dystrophic neurite formation $[19,52,53]$, but the role of $A \beta$ is poorly understood. We recently determined that BACE1-YFP expressed from a doxycycline-inducible transgene lacking the endogenous 5' UTR that controls BACE1 translation accumulates around plaques in an APP transgenic mouse similar to that observed in AD [48]. These results suggest that BACE1 elevation in $\mathrm{AD}$ occurs via a post-translational mechanism involving $A \beta$ neurotoxicity that is closely associated with amyloid plaques, and does not appear to involve transcriptional or translational regulation.

Here, we show by live-cell imaging that $\mathrm{A} \beta 42$ oligomers cause microtubule disruption and neuritic beading. In BACE1-positive dystrophic neurites surrounding amyloid plaques of $\mathrm{AD}$ and the 5XFAD transgenic mouse model, tubulin isoforms are mis-localized, often forming aberrant accumulations or voids. By EM, 5XFAD dystrophic axons appear distended with multi-lamellar vesicles, but notably lack intact microtubules. This observation, together with aberrant localization of microtubule motor proteins and other neuronal proteins, and evidence of reduced lysosomal function and autophagic intermediate accumulation, suggests that microtubule-based transport is impaired in dystrophic neurites surrounding amyloid plaques. Most importantly, BACE1 and APP accumulate in peri-plaque dystrophies to very high levels and lead to increased generation of BACE1-cleaved APP products, including A $\beta 42$ that may exacerbate plaque growth. Taken together, our results suggest that amyloid plaques cause a local toxic effect, possibly mediated by soluble $A \beta 42$ oligomers, that generates presynaptic dystrophic neurites by disrupting microtubles and impairing transport. As a result, peri-plaque dystrophies accumulate BACE1, APP, and $\gamma$-secretase, further contributing to $A \beta$ generation and plaque growth in a feedforward mechanism.

\section{Materials and methods}

\section{Primary neuron culture, A $\beta 42$ oligomer preparation, and immunofluorescence}

E15.5-16.5 C57BL/6 mouse cortical neurons were plated on poly-L-lysine (Sigma) coverslips in 12-well plates $(150,000$ cells/well $)$ in neurobasal media supplemented with $2 \% \mathrm{~B}-27,500 \mu \mathrm{M}$ glutamine, $10 \%$ horse serum, and $2.5 \mu \mathrm{M}$ glutamate. After $2 \mathrm{~h}$, medium was changed to neurobasal with $2 \%$ B-27, $500 \mu \mathrm{M}$ glutamine, and $2.5 \mu \mathrm{M}$ glutamate. After 1-3 days, medium was replaced with neurobasal plus $2 \% \mathrm{~B}-27$ and $500 \mu \mathrm{M}$ glutamine. Following 9 days in culture, neurons were treated with $1 \mu \mathrm{M} \mathrm{A} \beta 42$ oligomers or vehicle prepared as previously described [48, 55]. Briefly, lyophilized recombinant $\mathrm{A} \beta 42$ peptide (rPeptide, cat\# A-1163-1) was HFIP treated, dried down, then resuspended to $5 \mathrm{mM}$ in dry DMSO (Molecular Probes, \# D12345) and brought to $100 \mu \mathrm{M}$ in cold, $4 \mathrm{mM}$ HEPES $\mathrm{pH} 8$, incubated on ice at $4{ }^{\circ} \mathrm{C}$ for $24 \mathrm{~h}$ to generate oligomers. For control cultures, DMSO alone was added to $4 \mathrm{mM}$ HEPES $\mathrm{pH} 8$ and incubated as described. After $72 \mathrm{~h}$ 
of A $\beta 42$ treatment, neurons were fixed for $20 \mathrm{~min}$ in $4 \%$ paraformaldehyde, $0.12 \mathrm{M}$ sucrose in PBS, permeabilized in $0.5 \%$ Triton, and incubated in anti- $\beta$ III tubulin mouse monoclonal antibody (TuJ1, gift of Dr. Lester Binder, 1:500) followed by donkey anti-mouse Alexa 568-conjugated secondary antibody (Molecular Probes, 1:1000) and counterstained with 300 nM DAPI. Coverslips were mounted using Prolong Gold (Molecular Probes), and images acquired on a Nikon A1 confocal microscope with a $60 \times$ objective (NA 1.4) and NIS Elements software.

\section{Live imaging of neurons}

Primary neurons prepared as above were plated $(150,000$ cells/dish) in 35-mm glass-bottom culture dishes (MatTek \# P35G-1.5-14C). After 11-12 days, medium was replaced with neurobasal containing $250 \mathrm{nM}$ of Tubulin Tracker (Molecular Probes \#T34075), neurons incubated for $30 \mathrm{~min}$ at $37^{\circ} \mathrm{C}$, rinsed twice with warmed media, and original media replaced. $10 \mu \mathrm{M} \mathrm{A} \beta 42$ oligomers or vehicle, prepared as above, were added and neurons imaged on an Andor Spinning Disk confocal microscope with a $60 \times$ objective (NA 1.49). Imaging began within $30 \mathrm{~min}$ of treatment and continued for $3 \mathrm{~h}$, with a 100-ms exposure taken every $5 \mathrm{~min}$, or $6 \mathrm{~h}$, with a 100-ms exposure taken every hour, at 20-25 locations on the coverslip. Images were captured using Metamorph and intensity quantified in ImageJ. Statistical analysis was done using a two-tailed $t$ test in Prism.

\section{Mice}

5XFAD mice were generated as previously described [40] and maintained by crossing transgene positive males with B6/SJL F1 hybrid females (Jackson Laboratories). As negative controls, 5XFAD mice were crossed to BACE1 ${ }^{-1-}$ mice [4] to generate 5XFAD;BACE1-/- mice. All animal work was done in accordance with Northwestern University IACUC approval.

\section{Human tissue immunofluorescence}

Human post-mortem brain tissue was obtained from three AD patients and three cognitively normal controls (Supplementary Table S2) diagnosed at the Cognitive Neurology and Alzheimer's Disease Center with approval from the Northwestern University IRB. 40- $\mu \mathrm{m}$ floating sections of superior temporal gyrus were stained and imaged as described for murine tissue, except that primary and secondary antibody incubations were $48 \mathrm{~h}$ at $4{ }^{\circ} \mathrm{C}$ to improve antibody penetration, methoxy XO4 was added after secondary antibody incubation to label plaques, and $0.2 \%$ Sudan Black in $40 \%$ ethanol was used to quench autofluorescence. Sections incubated in parallel without primary antibody were included as negative controls for autofluorescence and background binding of secondary antibody. A minimum of 10 plaques per case were imaged and analyzed on a Nikon A1 confocal microscope with a $60 \times$ objective (NA 1.4) and NIS Elements software. Image acquisition settings were maintained the same between $\mathrm{AD}$ and control cases. We note that the $\beta$ III-tubulin antibody TuJ1 is very well characterized and produced the expected $\beta$ III-tubulin staining pattern in cognitively normal controls (not shown) and in normal-appearing neuropil in AD cases (Fig. 3a, c), which served as positive controls. The no-primary antibody negative control produced only weak non-specific background staining in control and AD brain sections (not shown).

\section{Murine tissue immunofluorescence}

Mice were perfused with ice-cold PBS containing protease and phosphatase inhibitors (Calbiochem), brains harvested, and one hemibrain/mouse drop fixed in $4 \%$ paraformaldehyde/PBS and cryopreserved in $30 \% \mathrm{w} / \mathrm{v}$ sucrose/PBS for sectioning. The other hemibrain/mouse was dissected into cortex and hippocampus and flash frozen in LN2 for biochemistry. $30-\mu \mathrm{m}$ coronal or sagittal floating brain sections were cut and subjected to antigen retrieval for $1 \mathrm{~h}$ at $80^{\circ} \mathrm{C}$ in $0.1 \mathrm{M}$ sodium citrate $\mathrm{pH} 9$ followed by $16 \mathrm{mM}$ glycine in Tris-Buffered Saline with $0.25 \%$ triton-X 100 (TBST) and blocked in $5 \%$ donkey serum in TBS-T. Sections were incubated overnight at $4{ }^{\circ} \mathrm{C}$ with primary antibodies listed in Supplementary Table 1, followed by secondary antibodies (donkey anti-mouse, rabbit or goat conjugated to Alexa 488, 568 or 647; Molecular Probes) used at the same concentration as primary antibody for $2-3 \mathrm{~h}$ at room temperature (except $4{ }^{\circ} \mathrm{C}$ overnight to improve penetration in the case of anti-tubulin antibodies) plus $300 \mathrm{nM}$ DAPI. Sections incubated in parallel without primary antibody were included as negative controls for autofluorescence and background binding of secondary antibody. Sections were mounted with Prolong Gold (Molecular Probes) and images acquired on a Nikon A1 confocal microscope with a $60 \times$ objective (NA 1.4) and NIS Elements software. All image acquisition settings were maintained the same between genotypes (5XFAD;BACE1+/+ and 5XFAD;BACE1-/-). For all proteins whose plaque-associated co-localization with BACE1 was not previously published, 5-8 male and female 5XFAD mice at 5-6 or 9 months of age (Table S3) were analyzed, and 20-40 plaques were imaged for each antibody stain. For co-localization patterns of proteins with BACE1 that have been previously published (Table S4), we did not include additional mice but did confirm the originally reported staining patterns for $\beta$ III-tubulin (Fig. 3), MAP2 (Fig. 6), synaptophysin (Fig. 6), APP (Figs. 8, 9), 
and $\mathrm{A} \beta / 3 \mathrm{D} 6$ (Figs. 8, 9). We validated neoepitope antibodies to APP cleavage products using brain sections from 5XFAD;BACE1-/- mice (negative control). These sections were processed and imaged in parallel with brain sections from 5XFAD;BACE1+/+ mice. For other antibodies, we considered normal-appearing neuropil regions distant from plaques to be an internal positive control, as well as normal-appearing regions of the stratum lucidum (Fig. 6, bottom row), which serves as a positive control for normal BACE1 localization and co-localization with other proteins.

\section{Electron microscopy}

5XFAD mouse brain tissue was prepared for electron microscopy as previously described [25]. Briefly, mice were anesthetized with isofluorane (Isothesia, Butler), perfused transcardially with $0.12 \mathrm{M}$ PBS ( $\mathrm{pH} 7.4)$ for $1 \mathrm{~min}$, then a dilute aldehyde mixture (1\% paraformaldehyde, $1.25 \%$ glutaraldehyde, $0.02 \mathrm{mM} \mathrm{CaCl}$ in $0.1 \mathrm{M}$ sodium cacodylate buffer) for $30 \mathrm{~min}$, and a concentrated aldehyde mixture $(2 \%$ paraformaldehyde, $2.5 \%$ glutaraldehyde, $0.04 \mathrm{mM} \mathrm{CaCl}_{2}$ in $0.1 \mathrm{M}$ sodium cacodylate buffer) for $10 \mathrm{~min}$. The brain was removed and placed in ice-cold concentrated fixative on a shaker at $4{ }^{\circ} \mathrm{C}$ overnight. The following day brain was bisected, rinsed $3 \times 20 \mathrm{~min}$ in $0.12 \mathrm{M}$ TBS and cut into $70 \mu \mathrm{m}$ coronal sections. Sections were washed in $0.12 \mathrm{M}$ phosphate buffer (PB) $3 \times$ 10 min at $4{ }^{\circ} \mathrm{C}$, treated with $2 \% \mathrm{OsO}_{4}$ in $0.12 \mathrm{M} \mathrm{PB}$ for $1 \mathrm{~h}$ at $4{ }^{\circ} \mathrm{C}$, and washed $3 \times 10 \mathrm{~min}$ in $0.12 \mathrm{M} \mathrm{PB}$. The tissue was then dehydrated in graded ethanols and propylene oxide, infiltrated with 1:1 araldite:propylene oxide, flat embedded between aclar sheets and cured for $48 \mathrm{~h}$ at $60{ }^{\circ} \mathrm{C}$. Regions of interest were subdissected and re-embedded as above. Serial ultrathin sections $(65 \mathrm{~nm})$ were cut, placed onto formvar-coated slotted grids, then stained with $5 \%$ aqueous uranyl acetate for $15 \mathrm{~min}$, followed by Reynold's lead citrate $(1.33 \mathrm{~g}$ lead nitrate, $1.76 \mathrm{~g}$ sodium citrate, $30 \mathrm{ml}$ distilled water, $8 \mathrm{ml}$ of $1 \mathrm{~N} \mathrm{NaOH}$, then diluted to $50 \mathrm{ml}$ ) for $10 \mathrm{~min}$, and rinsed in ultrapure $\mathrm{dH}_{2} \mathrm{O}$. Images (7500-20,000 $\times$ ) were acquired on a JEOL 1200EX electron microscope (JEOL Ltd., IL, USA) from 10 to 30 serial sections. ImageJ software was used for processing image stacks of serial sections.

\section{Immunoblotting}

Frozen brain tissue was homogenized in RIPA buffer and $20 \mu \mathrm{g}$ of homogenate separated by $10 \%$ tris-glycine SDS-PAGE. Protein was transferred onto $0.45 \mu \mathrm{m}$ PVDF membrane, stained with $0.1 \%$ Ponceau, and imaged. Blots were incubated with anti-APP antibody (6E10, Covance Sig-39300 1:2000) or anti-cathepsin D (Abcam \# ab75852
1:1000) followed by HRP-conjugated anti-mouse or antirabbit secondary antibody (Vector Laboratories 1:10,000). Blots were visualized using chemiluminescence (Luminata Crescendo, Millipore), signals quantified using a Kodak Image Station $4000 \mathrm{R}$, normalized to Ponceau, densitometric analyses performed using Kodak 1D 3.6 image analysis software, and statistics analyzed in Prism GraphPad.

\section{Statistical analyses}

Statistical differences for immunoblot experiments were determined using two-tailed Student's $t$ test (GraphPad Prism Software, Inc., San Diego, CA, USA). Graphed data are presented as the mean \pm SEM, and $p<0.05$ was considered significant.

\section{Results}

\section{A $\beta 42$ causes neuritic beading and microtubule disruption in primary neurons in vitro}

In addition to amyloid plaques and neurofibrillary tangles, other hallmark lesions of the Alzheimer's disease brain include swollen, dystrophic neurites that surround amyloid plaques (reviewed in $[9,51]$ ). Since these dystrophic neurites are predominantly found in very close proximity to, and often in contact with, plaques [25, 62] a neurotoxic form of $\mathrm{A} \beta$ (e.g., oligomers) likely causes dystrophy formation. To test this hypothesis, we isolated primary cortical neurons from embryonic mice and exposed them to $1 \mu \mathrm{M}$ of oligomeric $\mathrm{A} \beta 42$ for $72 \mathrm{~h}$, then performed immunofluorescence microscopy for neuron-specific $\beta$ IIItubulin. A $\beta 42$-treated neurons displayed processes with numerous $\beta$ III-tubulin accumulations along their lengths resembling beads on a string, compared to vehicle-treated neurons (Fig. 1a). Neuritic beading was not likely associated with processes related to cell death caused by high concentrations of $A \beta 42$, since we previously observed that 5 days of treatment with 1 and $2 \mu \mathrm{M} \mathrm{A} \beta 42$ oligomers did not increase caspase 3 cleavages in primary neurons [49]. These beaded structures bore a striking resemblance to tubulin accumulations observed in dystrophic neurites around plaques in vivo (Fig. 3), suggesting a similar mechanism of generation. Our observation of tubulin accumulation in beaded processes in A $\beta 42$-treated cultured neurons is in agreement with extreme beading of primary neurons following 4 days of exposure to $15 \mu \mathrm{M} \mathrm{A} \beta 42$ [11].

Neuritic dystrophy and beading are observed in neurons exposed to a variety of stressors and may be part of a regulated neurite degeneration pathway separate from cellular apoptosis $[10,21,28]$. The presence of abnormal $\beta$ IIItubulin accumulations in $\mathrm{A} \beta 42$-treated primary neurons 

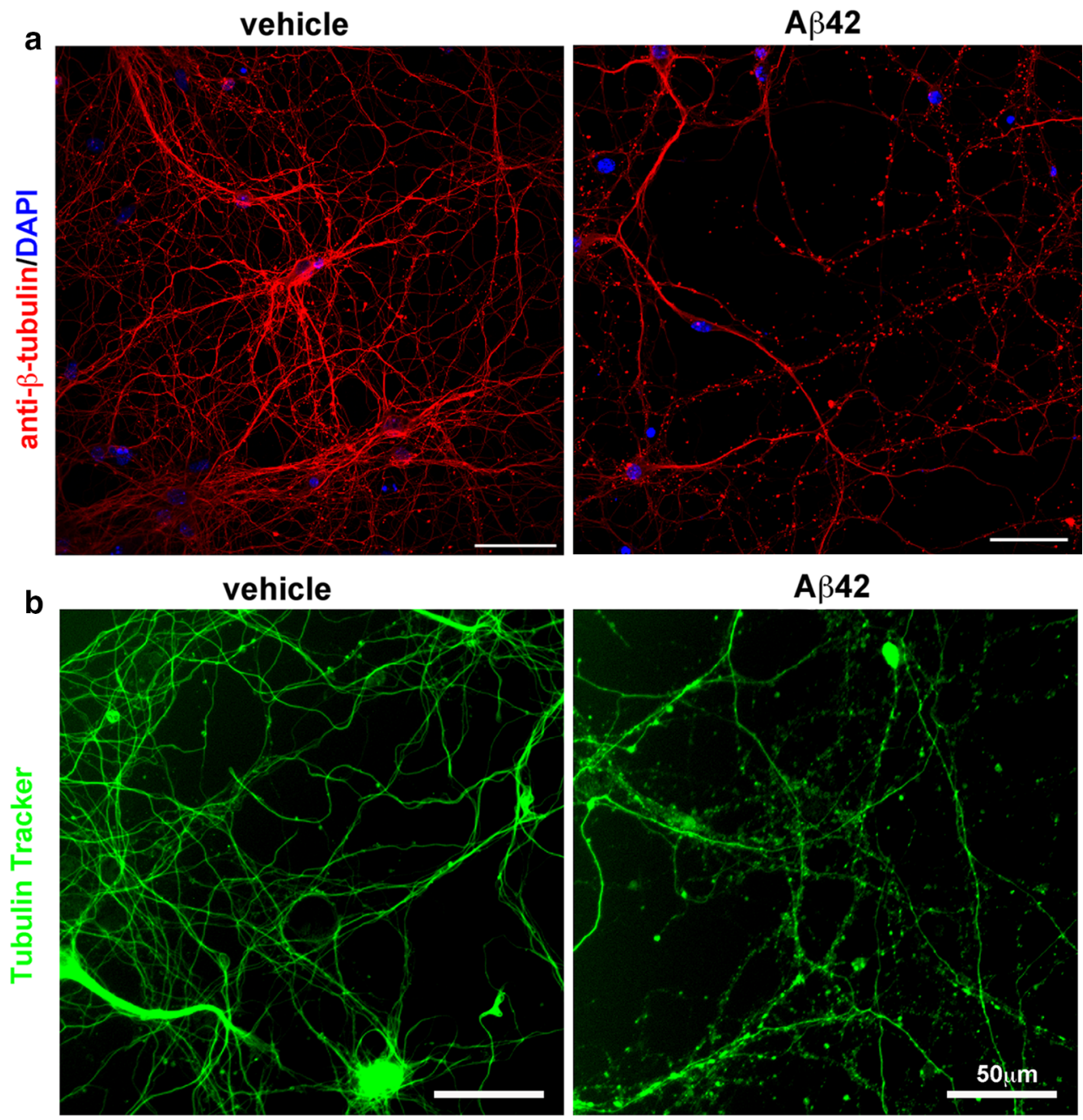

Fig. 1 Oligomeric A $\beta 42$ causes neurite beading and microtubule disruption in primary neurons. a Primary cortical neurons were cultured from e15.5 mouse embryos and after 9 days in vitro were exposed to $1 \mu \mathrm{M}$ A $\beta 42$ oligomers or vehicle. After $72 \mathrm{~h}$, coverslips were fixed in $4 \%$ paraformaldehyde, permeabilized, and stained with the antibody TuJ1 against $\beta$ III-tubulin (red) and DAPI (blue). Neurite beading is very prominent in A $\beta 42$-treated cultures, while neurites appear smooth and unbeaded in vehicle-treated neurons. b Primary neurons were isolated as described in $\mathbf{a}$, and after 12 days in vitro were exposed to $10 \mu \mathrm{M} \mathrm{A} \beta 42$ oligomers or vehicle. After $22 \mathrm{~h}$ of

suggested that $A \beta 42$ could disrupt microtubule networks, and that impaired axonal transport could be a specific and early effect of $A \beta 42$ leading to serious neuronal and synaptic dysfunction. To test this hypothesis, we followed microtubule dynamics in real time by live-cell imaging to determine if and when $\mathrm{A} \beta 42$ could cause microtubule disruption. We incubated primary neurons with Tubulin Tracker (Oregon Green-labeled taxol) that binds only to polymerized tubulin in microtubules, and then exposed the neurons to $10 \mu \mathrm{M} \mathrm{A} \beta 42$ oligomers (Fig. 1b) to model the potentially high $\mathrm{A} \beta 42$ oligomer concentrations in the immediate vicinity of amyloid deposits [29]. After $22 \mathrm{~h}$
A $\beta 42$ treatment, the fluorescent microtubule probe Tubulin Tracker was added to a final concentration of $250 \mathrm{nM}$ for $30 \mathrm{~min}$. Unfixed, live neurons were then imaged at $\times 20$ using a Nikon Eclipse TS100 microscope with NIS Elements software. Note that $A \beta 42$-induced neurite beading visualized by Tubulin Tracker appears very similar to that observed with $\beta$ III-tubulin immunostaining in $\mathbf{a}$, and occurs more rapidly with higher $A \beta 42$ concentration. Taken together, these results strongly suggest that $A \beta 42$ disrupts the organization of microtubules in neurons. Scale bars in all frames $50 \mu \mathrm{m}$

of treatment, neuritic beading that strongly resembled the previously observed aberrant $\beta$ III-tubulin immunostaining pattern (Fig. 1a) was apparent in live A $\beta 42$-treated Tubulin Tracker-labeled neuron cultures (Fig. 1b), while vehicle-treated neurons remained healthy with mostly smooth processes. These findings suggested that $\mathrm{A} \beta 42$ exposure results in microtubule disruption leading to abnormal tubulin accumulation and neuritic beading in neurons.

To determine how early microtubule disruption and neuritic beading occur after exposure to $A \beta 42$, we used spinning disk confocal microscopy to image live Tubulin Tracker-labeled primary neurons continuously every 5 
min after $10 \mu \mathrm{M} \mathrm{A} \beta 42$ oligomer or vehicle treatment. We observed that noticeable microtubule disruption and beading occurred on neurites of primary neurons as early as $3.5 \mathrm{~h}$ following A $\beta 42$ treatment, while vehicle-treated cultures appeared normal (Figs. 2a, S1). The very early appearance of disrupted microtubules in beaded neurites suggested that this is one of the primary ways in which $A \beta 42$ oligomers could impair neuronal function. Also, differential interference contrast microscopy indicated that most of the neurites with beads or aberrant microtubule organization were still continuous and intact, although morphologically abnormal (Figs. 2a, S1). These results were highly reproducible, as they were representative of six individual experiments, all performed using separate primary neuron and $\mathrm{A} \beta 42$ preparations. We also observed a greater overall decrease in Tubulin Tracker fluorescence after $3 \mathrm{~h}$ in the A $\beta 42$-treated neurons compared to vehicle (Fig. 2b), suggesting that $A \beta 42$ causes microtubule depolymerization. To limit photodamage, we performed an identical live-imaging experiment, except capturing an image once every hour for $6 \mathrm{~h}$, and observed even more striking neuritic beading and microtubule disruption in A $\beta 42$-treated neurons, while vehicle-treated neurons showed very little change (Fig. 2c).

A $\beta 42$ oligomer concentrations in the range of $1-10 \mu \mathrm{M}$ induce cell death in primary neuron culture (reviewed in [16]). To determine whether neuritic beading and microtubule disruption were the results of A $\beta 42$-induced cell death processes, we repeated Tubulin Tracker labeling of primary neurons followed by $\mathrm{A} \beta 42$ treatment for $3.5 \mathrm{~h}$, then added propidium iodide to label the nuclei of dead cells (Fig. S1). Although we noted $\mathrm{A} \beta 42$-induced neuritic beading and microtubule disruption (Fig. S1a), the percentage of live cells as measured by absence of propidium iodide uptake was identical for both A $\beta 42$-treated and vehicle control neurons (Fig. S1b). This result demonstrates that neuritic beading and microtubule disruption precede the induction of cell death in $\mathrm{A} \beta 42$-treated primary neurons.

The A $\beta 42$-induced reduction and aberrant spatial distribution of microtubules in neurites suggested that microtubule-based transport would be impaired in $A \beta 42$-treated primary neurons. It has also been reported that trafficking of BDNF [44] mitochondria [70], and other axonal cargo [57] is impaired by $\mathrm{A} \beta$, so we hypothesized BACE1 transport may be affected as well. To test this hypothesis, we transfected primary neurons with BACE1-YFP and neuropeptide Y-mCherry (NPY-mCherry) fusion constructs, treated with $10 \mu \mathrm{M}$ A $\beta 42$ oligomers or vehicle, and performed live-cell imaging and kymograph analysis to assess vesicular movement in neurites. We observed that the proportion of motile BACE1-YFP and NPY-mCherry puncta was decreased in neurites of $A \beta 42$-treated neurons, compared to vehicle (Fig. S2). We infer that the effect of $\mathrm{A} \beta 42$ on trafficking in neurites is not limited to BACE1-containing vesicles, as the movement of NPY-mCherry puncta was also decreased. Taken together, our results suggest that $\mathrm{A} \beta 42$ causes microtubule depolymerization and network disruption, leading to neuritic beading and impaired microtubule-based axonal transport in neurons.

\section{Tubulin is aberrantly localized and microtubules are disrupted in peri-plaque presynaptic dystrophic neurites in vivo}

In both AD and APP transgenic mouse brains, BACE1 accumulates in swollen presynaptic dystrophic neurites that surround amyloid plaques in close proximity $[25,85$, 86]. To gain insight into the mechanism of $A \beta$-induced BACE1 elevation in peri-plaque dystrophies and the potential role of microtubules, we performed immunofluorescence staining of superior temporal gyrus from $\mathrm{AD}$ patients and cognitively normal controls (Table S2) with antibodies against BACE1 and neuron-specific BIIItubulin, as well as methoxy $\mathrm{XO} 4$ to label fibrillar amyloid deposits. As we have previously reported [25, 86], in AD brain BACE1 immunoreactivity was elevated in dystrophic neurites in a halo pattern immediately surrounding the methoxy XO4-positive amyloid plaque core. Interestingly, we observed a striking reduction of $\beta$ III-tubulin signal within the BACE1-positive peri-plaque halo, while the pattern of $\beta$ III-tubulin immunoreactivity seemed unaffected in nearby normal-appearing neuropil (Fig. 3a, first two columns; Fig. S3, first column) and in cognitively normal controls (not shown). To determine the quantitative relationships between BACE1 and $\beta$ III-tubulin immunoreactivities within the peri-plaque halo, we calculated the ratio of BACE1 to $\beta$ III-tubulin immunofluorescence intensities in dystrophic neurites (defined by high BACE1 signal) around plaques and in regions of normal neuropil distant from plaques for the AD cases (Fig. 3b). Importantly, we observed that the peri-plaque BACE1: $\beta$ III-tubulin ratio was significantly elevated (Fig. 3b, first two panels). We also generated intensity profiles of BACE1 and $\beta I I I-$ tubulin immunofluorescence signals through the plaque, and generally found an inverse relationship between BACE1 and $\beta$ III-tubulin intensities, such that high BACE1 signal typically occurred in areas of low $\beta$ III-tubulin intensity (Fig. 3c, first two columns). In cognitively normal controls, no plaques, and hence no areas of elevated BACE1 or loss of $\beta$ III-tubulin, were observed (not shown). These results confirm and extend our initial observation of decreased $\beta$ III-tubulin staining around plaques in $\mathrm{AD}$ [86]. Moreover, they suggest that reduced tubulin level, and hence low microtubule density, in dystrophic regions surrounding plaques is a pathologic feature of $\mathrm{AD}$ that is the consequence of short-range $A \beta$ toxicity to neurites, and may have a role in BACE1 accumulation. 

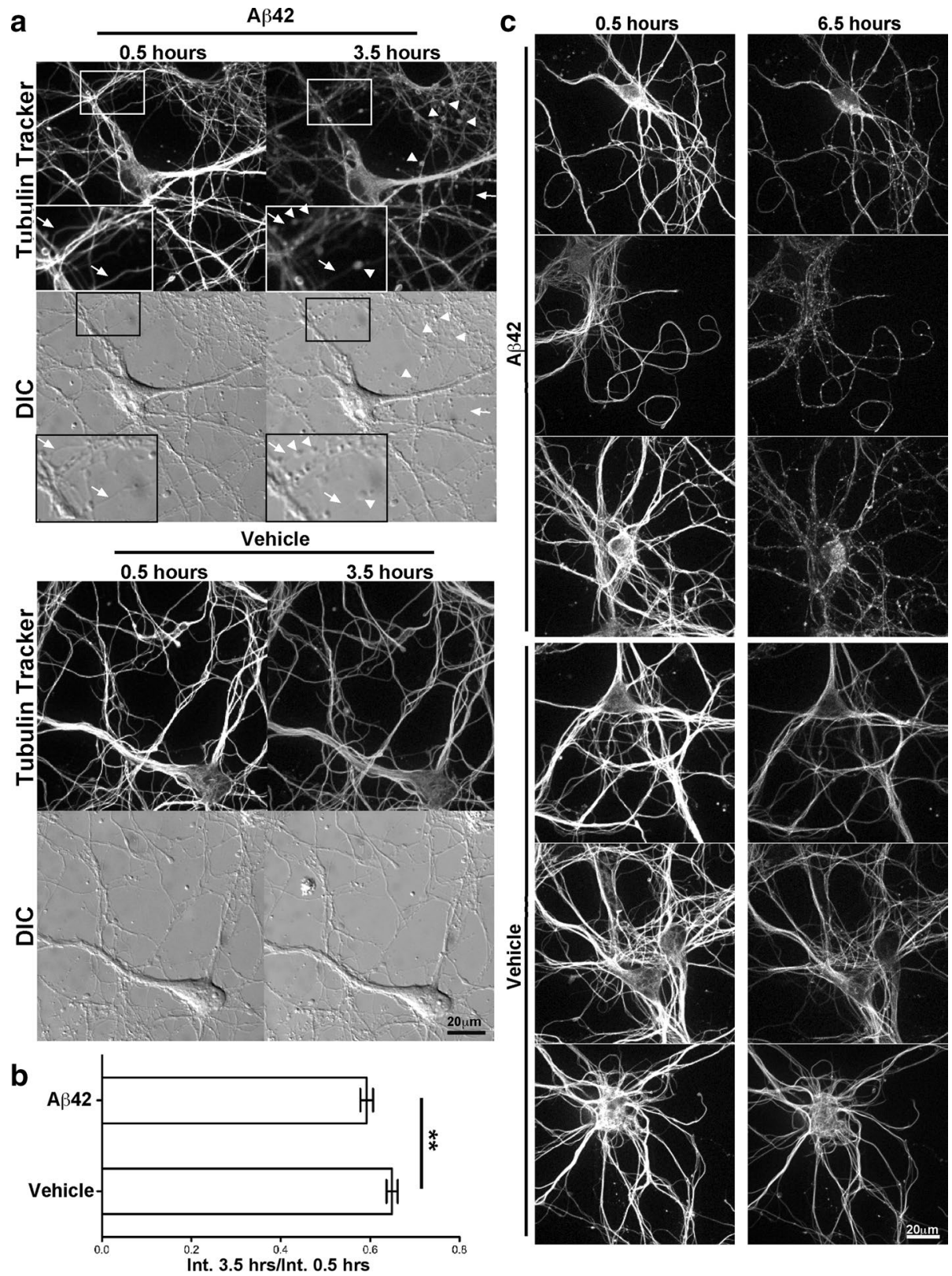

Fig. 2 Microtubule disruption in primary neurons is an early response to oligomeric $A \beta 42$. Primary cortical neurons were cultured as in Fig. 1, and after 12 days in vitro, were labeled for $30 \mathrm{~min}$ with $250 \mathrm{nM}$ Tubulin Tracker, rinsed, and then exposed to $10 \mu \mathrm{M}$ A $\beta 42$ oligomers or vehicle. Live imaging on an Andor spinning disk confocal microscope began $30 \mathrm{~min}$ after addition of $\mathrm{A} \beta 42$. a Fluorescence and differential interference contrast (DIC) images were acquired every 5 $\min$ for $3 \mathrm{~h}$. Neurite beading, microtubule accumulation in varicosities (arrowheads), and microtubule fragmentation (arrows) in neurites were present $3.5 \mathrm{~h}$ after $\mathrm{A} \beta 42$ addition, in the absence of significant cell death or BACE1 elevation [49]. In contrast, the morphology of vehicle-treated neurons was unaffected, with the exception of a moderate decrease of fluorescence intensity. DIC imaging revealed that neurites of A 342 -treated neurons were intact and continuous, even though they exhibited beading and microtubule fragmentation, indicating that the observed microtubule disruption was not the result of physical degeneration of neurites. Insets show higher magnification images of the boxed region of the $\mathrm{A} \beta 42$-treated culture to accentuate varicosity for-

mation and microtubule fragmentation. b The ratios of Tubulin Tracker fluorescence intensity (Int.) at $3.5 \mathrm{~h}$ (hours) to that at $0.5 \mathrm{~h}$ after $\mathrm{A} \beta 42$ treatment were calculated for 46 image fields from two separate experiments and averaged for $\mathrm{A} \beta 42$-treated and vehicle-treated neurons. Overall Tubulin Tracker fluorescence intensity decreased in neurons over time due to photo-bleaching, as indicated by fluorescence intensity ratios below 1 . Nevertheless, the Tubulin Tracker fluorescence intensity ratio for $A \beta 42$-treated neurons showed a small but highly significant decrease compared to vehicle treatment $(p=0.004)$, suggesting microtubule depolymerization and reduced stability of microtubule networks after only $3.5 \mathrm{~h}$ of A 442 exposure. Error bars SEM; **, $p<0.01$. c To investigate longer $\mathrm{A} \beta 42$ treatment times and minimize photo-bleaching, primary neuron cultures were prepared as above and images collected once every $60 \mathrm{~min}$ for $6 \mathrm{~h}$. Neurite beading, aberrant microtubule localization, and microtubule fragmentation were even more prevalent and pronounced in neurons after $6.5 \mathrm{~h}$ compared to $3.5 \mathrm{~h}$ of A $\beta 42$ treatment, while vehicle-treated neurites continued to appear normal. Scale bars $20 \mu \mathrm{m}$ for all images in $\mathbf{a}, \mathbf{c}$ 


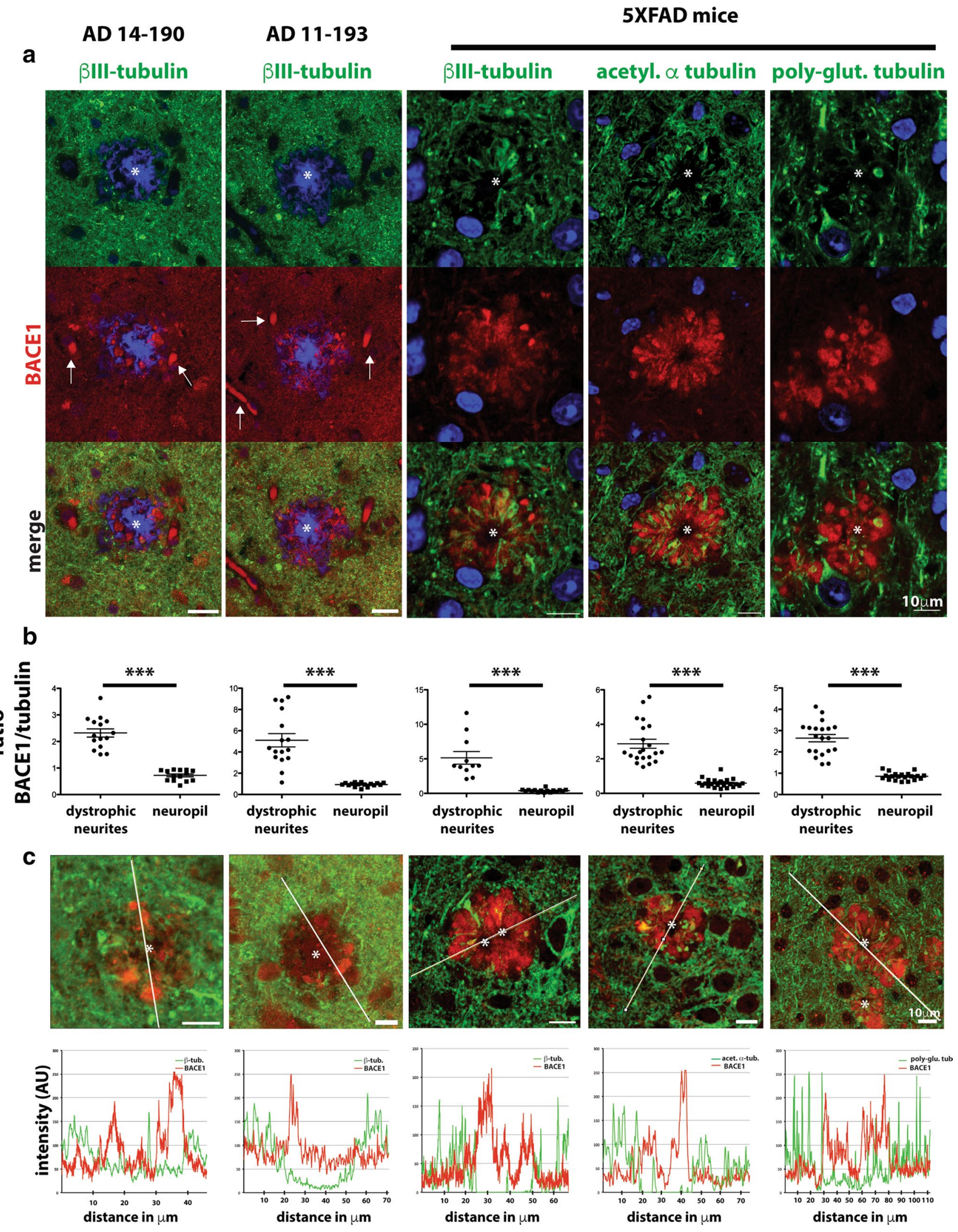


4Fig. 3 Tubulin isoforms are aberrantly localized in BACE1-positive peri-plaque dystrophic neurites in vivo. a Post-mortem brain sections of superior frontal gyrus from three AD patients and three cognitively normal controls were stained with antibodies against BACE1 (red) and BIII-tubulin (green), and methoxy XO4 (blue) to label amyloid deposits. Representative plaques from two cases (AD 14-190 and AD 11-193, Columns 1-2) are shown; additional examples in Fig. S2. Cognitively normal controls were negative for plaques, as expected (not shown). As previously reported [86], BACE1 immunostaining was observed in a halo of dystrophic neurites surrounding individual plaques. In contrast, $\beta$ III-tubulin immunostaining was almost entirely absent in peri-plaque BACE1-positive dystrophies. Non-dystrophic neuropil in areas adjacent to plaques exhibited normal intensities and patterns of $\beta$ III-tubulin immunostaining. Some red fluorescence (white arrows) represents non-specific background from blood vessels. Brain sections from the aggressive amyloid 5XFAD mouse model were stained with antibodies against BACE1 (red) and BIII-tubulin, acetylated $\alpha$-tubulin or polyglutamylated tubulin (green). Representative 5XFAD amyloid deposits are shown (Columns 3-5), with plaque cores marked by asterisks; additional examples in Fig. S2. Similar to human $\mathrm{AD}, \mathrm{BACE} 1$ accumulated in peri-plaque dystrophic neurites in 5XFAD brain sections. Additionally, the different tubulin isoforms were generally reduced in dystrophic halos around plaques, although tubulins often occurred in amorphous accumulations that showed little co-localization with BACE1 immunostaining. Scale bars in all frames $10 \mu \mathrm{m}$. b Immunofluorescence intensities of BACE1 and tubulin isoforms (as indicated at top of each column) in peri-plaque dystrophic neurites were measured and BACE1/tubulin intensity ratios calculated and compared to those in normal-appearing regions of neuropil within the same frame (Supplementary Methods). For human tissue, 16 dystrophies and corresponding non-dystrophic regions were measured per case. For murine tissue, BACE1/tubulin isoform ratios were determined for 11-20 BACE1-positive dystrophic regions and a corresponding number of nearby neuropil areas. BACE1/tubulin ratios for AD 14-190 and AD 11-193 (Panels 1 and 2, respectively) and 5XFAD mice (Panels 3-5) are shown. While there was substantial variation for dystrophic neurites, BACE1/tubulin intensity ratios for dystrophies were significantly elevated compared to those for normal neuropil for both AD cases and 5XFAD mice. Error bars SEM; $* * * p<0.001$. c The quantitative relationships between BACE1 and tubulin isoform immunofluorescence intensities by another method, intensity profiles as a function of distance across the plaque were generated (Supplementary Methods). Representative plaques are shown (upper row) for AD 14-190 and AD 11-193 (Panels 1 and 2, respectively) and 5XFAD mice (Panels 3-5). White line indicates path through plaque from which the intensity profiles were generated (bottom row). Note the inverse relationships between BACE1 and tubulin intensities as a function of distance across the plaque in each case. Taken together, these results suggest that tubulin, and hence microtubules, is reduced and/or mis-localized in peri-plaque dystrophic neurites. $A U$ arbitrary units. Scale bars in all frames $10 \mu \mathrm{m}$

Post-mortem AD brain samples represent end-stage disease and thus provide limited information about pathogenesis. To gain insight into the development of $A \beta$-induced dystrophic neurites, we turned to our 5XFAD mouse model of amyloid pathology [40]. Our previous work showed that brains of AD patients and 5XFAD mice have elevated levels of BACE1 that accumulate in dystrophic presynaptic neuronal structures (likely axons and terminals) in a halo that surrounds the amyloid deposit [86]. Taken together, these and other data suggest that the 5XFAD mouse is a faithful model of BACE1 elevation in AD.
To assess the distributions of tubulin and BACE1 around amyloid deposits in our AD mouse model, we immunostained brain sections from five different 5- to 6-monthold 5XFAD mice with antibodies directed against specific isoforms of tubulin, including neuron-specific $\beta$ III-tubulin, acetylated $\alpha$-tubulin, and polyglutamylated tubulin (Fig. 3a, third, fourth and fifth columns, respectively; Figs. S3, S4). BACE1 immunoreactivity was concentrated in a halo surrounding the core of the amyloid deposit, as previously reported [25, 85, 86]. Interestingly, similar to human AD, we observed that $\beta$ III-tubulin immunostaining was largely absent in BACE1-positive peri-plaque dystrophies. The $\beta$ III-tubulin signals that did occur in the peri-plaque halo appeared as amorphous accumulations with a staining pattern complementary to that of BACE1, i.e., regions of high $\beta$ III-tubulin intensity generally showed low BACE1 signal and vice versa. Acetylated and polyglutamylated isoforms of tubulin showed similarly reduced patterns of immunostaining in the peri-plaque halo. Additionally, we measured peri-plaque BACE1:tubulin ratios and intensity profiles for 5XFAD amyloid deposits (Fig. 3b, c) and found increased ratios and inverse relationships between BACE1 and tubulin isoforms, similar to our results for human AD plaques. We note that the peri-plaque human and mouse tubulin and BACE1 immunoreactivity patterns are similar but not identical, probably because mouse deposits are at most a few months old while human plaques are possibly many years old. At the end-stage of disease in post-mortem $\mathrm{AD}$ brain, there are very few, if any neurites near plaques that are not severely degenerated, thus potentially explaining the lower intensities of BACE1 and tubulin immunostaining in peri-plaque dystrophies of human $\mathrm{AD}$ compared to 5XFAD mouse.

The reduction in tubulin isoforms in 5XFAD BACE1positive dystrophies suggested that microtubules are decreased, disorganized, or disrupted in presynaptic dystrophic neurites near amyloid deposits. To investigate this possibility at an ultrastructural level, we examined ultrathin sections of 5XFAD mouse brain by electron microscopy (EM). We found swollen dystrophic neurites in abundance in close proximity or virtually contacting amyloid deposits (Fig. 4a). We confirmed the close physical association between BACE1-positive dystrophies and amyloid deposits in $3 \mathrm{D}$ reconstructions of multi-photon confocal microscopy images of live brain slices of BACE1-YFP;5XFAD multitransgenic mice (Supplementary Text; Fig. S5, Videos S1, S2). By BACE1 immuno-EM, we previously reported that dystrophies surrounding plaques are engorged with large BACE1-negative electron-dense multi-lamellar vesicles and smaller BACE1-positive electron-translucent vesicles [25]. Here, by EM we found dystrophies that were definitively identified as axons, as indicated by the presence of myelin sheaths (Fig. 4b-f). Importantly, we found occasional EM 

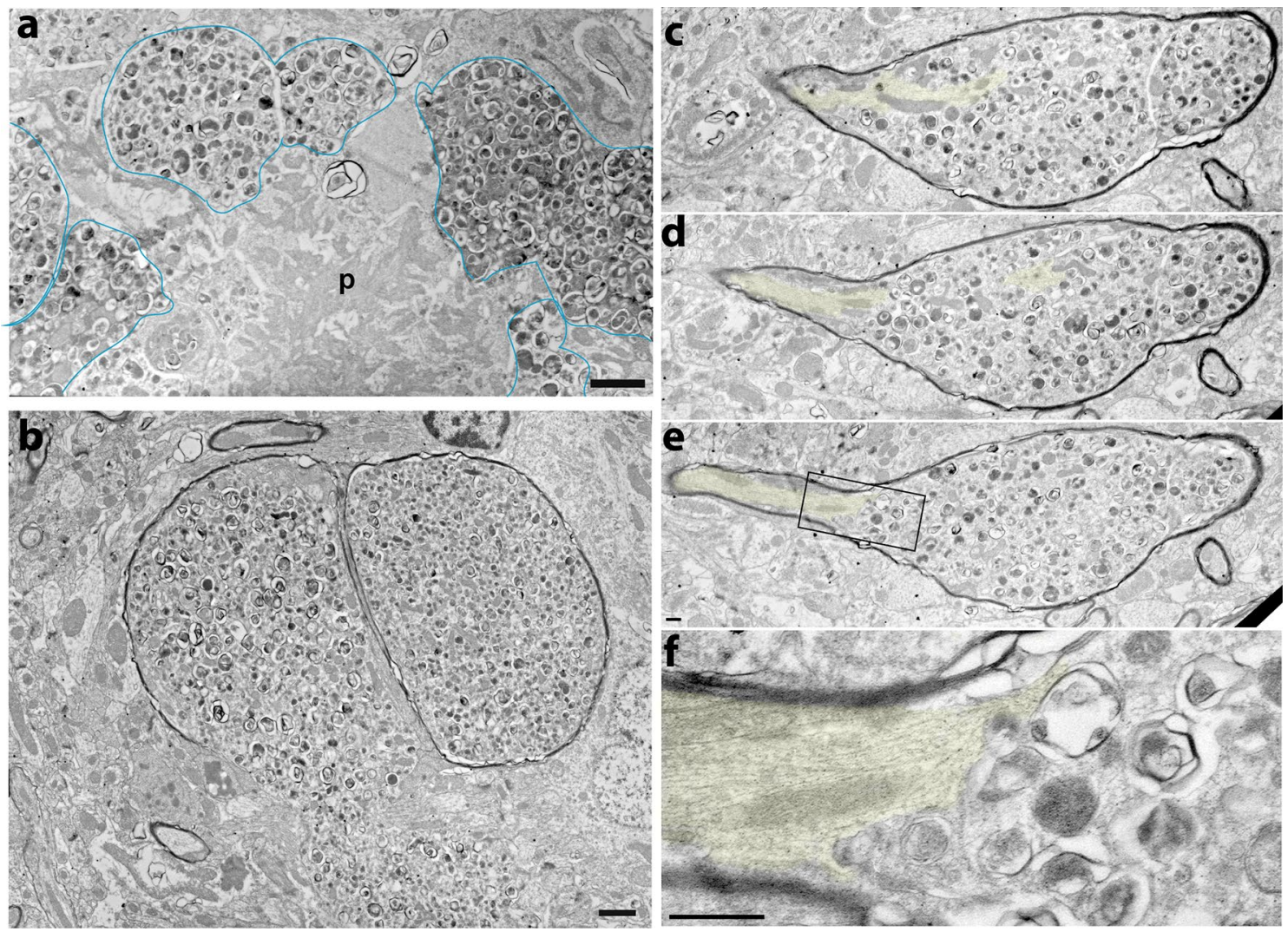

Fig. 4 Microtubules are strikingly absent in peri-plaque dystrophic axons. 5XFAD brain tissue was prepared for electron microscopy (EM) and assessed ultrastructurally for the presence of microtubules in peri-plaque dystrophic axons. a As previously reported [25], electron microscopy of 5XFAD brain revealed amyloid plaques (p) surrounded by dystrophic neurites (representative examples outlined in blue) filled with electron-dense multi-lamellar vesicles, possibly autophagic intermediates. b EM of a transverse section through a pair of dystrophic myelinated axons filled with multi-lamellar vesicles. Note that the lower portion of the axon on the left has lost its myelin sheath. c-f EM of serial ultrathin sections occasionally revealed series of longitudinal sections through dystrophic axons near amyloid plaques. Shown is such a series of a peri-plaque dystrophic myelinated axon with a portion of normal axon appearing on the left side of the dystrophy. Intact, continuous microtubules (yellow shading) are present in the morphologically normal part of the axon, but then microtubules become disorganized and mostly disappear within the dystrophic region. Note the dark outline of the surrounding myelin sheath, definitively confirming axonal identity. These ultrastructural images provide direct evidence that microtubules are disrupted and largely absent in peri-plaque dystrophic regions of axons. Images are spaced $\sim 200 \mathrm{~nm}$ apart. f Higher magnification of rectangle in e. Scale bars $1 \mu \mathrm{m}$ series displaying normal-appearing axons with dense microtubule bundles that enter a dystrophic region within which microtubules are strikingly absent, reduced in length, or dramatically disorganized (Fig. 4c-f). These data suggest that in human $\mathrm{AD}$ and in amyloid pathology mouse models, peri-plaque dystrophic axons are deficient in normal functional microtubule networks for axonal transport. Vesicles may enter but cannot transit or exit dystrophic regions due to absence of microtubules, which could explain the dramatic accumulation of BACE1 around plaques.

\section{Microtubule motor proteins are aberrantly localized in BACE1-positive peri-plaque dystrophic neurites}

Recent work has linked mutations in various proteins of the dynein-dynactin complex required for retrograde axonal transport to neurodegenerative disease in humans and mouse models [43]. If microtubule networks are disrupted in dystrophies around plaques, we reasoned that the microtubule motor proteins that move along them carrying cargo from the terminals back to the cell body could also be mis-localized, compounding the impaired removal of vesicles from dystrophic axons and terminals. This could lead to decreased turnover of proteins that are preferentially localized to presynaptic terminals, like BACE1 [25, 86]. To determine the localization pattern of microtubule motor proteins in peri-plaque dystrophies, we performed immunofluorescence microscopy of coronal brain sections from five individual 5- to 6-month-old 5XFAD mice using antibodies directed against cytoplasmic dynein intermediate chain (DIC), two subunits of dynactin (p150glued and dynamitin), and kinesin heavy chain (Figs. 5, S3, S4). DIC 

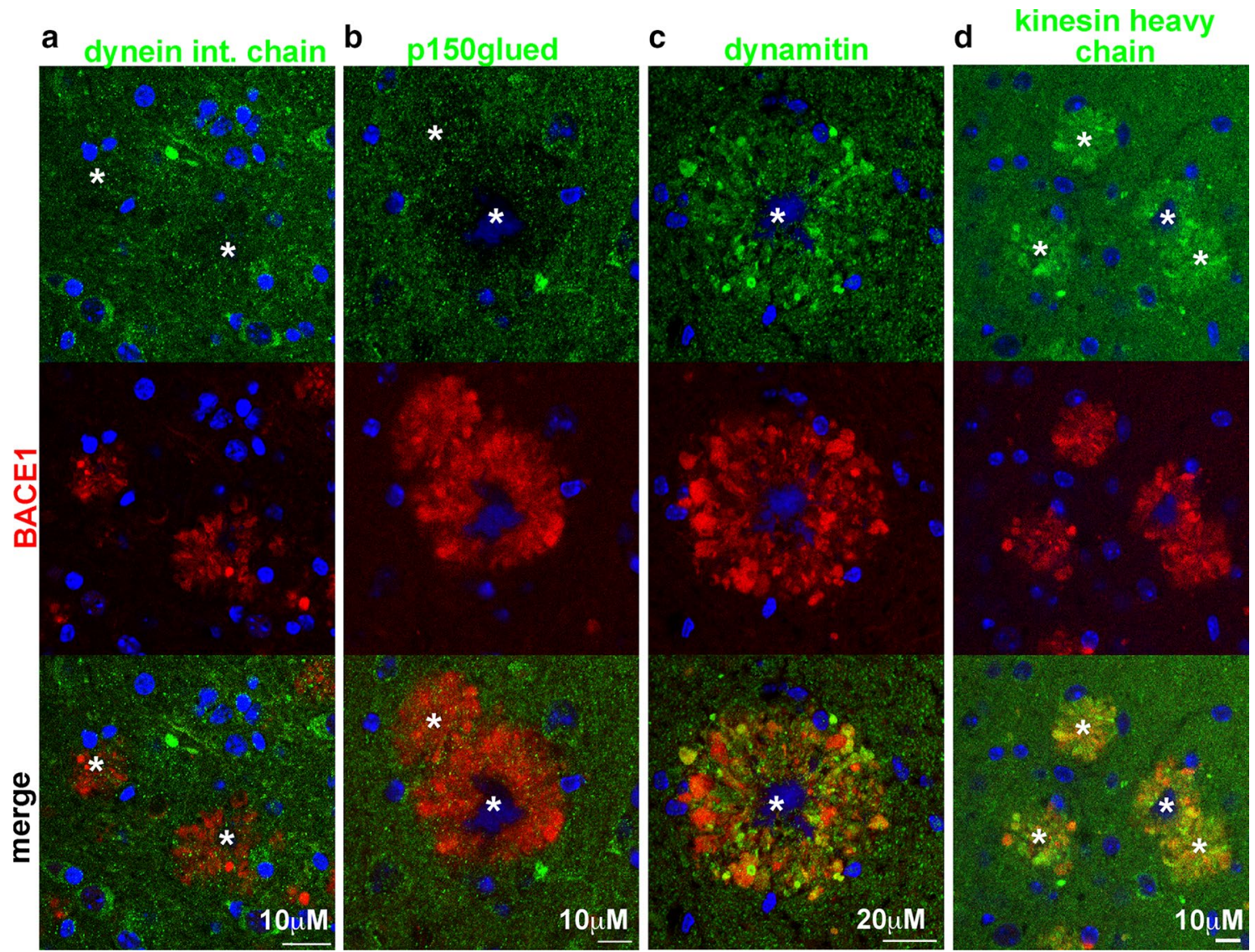

Fig. 5 Microtubule motor proteins are aberrantly localized in BACE1-positive peri-plaque dystrophic neurites. Sections from 5XFAD mouse brains were stained with antibodies against BACE1 (red) and various components of the dynein-dynactin retrograde transport complex, dynein intermediate chain (green, a), p150glued (green, b), dynamitin (green, c), or the anterograde motor protein kinesin heavy chain (green, d). Representative amyloid deposits are shown; additional examples in Figs. S3 and S4. Dynein intermediate

is a component of the retrograde microtubule motor, and while we observed some DIC staining in BACE1-positive dystrophic neurites, it was quite low compared to the amount of potential cargos such as BACE1 that accumulate in dystrophies (Figs. 5a, S3, S4). p150glued is required to initiate retrograde transport from the axon terminal [32, 37], stabilize microtubules in axons [30], and improve processivity of dynein $[27,35]$. Importantly, p150glued was diminished in BACE1-positive peri-plaque dystrophies compared to normal surrounding neuropil (Figs. 5b, S3, S4), suggesting a deficiency of functional and active retrograde dynein-dynactin complexes in these dystrophies. In contrast, dynamitin staining was noticeably increased in some, but not all, BACE1-positive peri-plaque dystrophies (Figs. 5c, S3, S4). Dynamitin tethers the cargo-binding domain of dynactin to the microtubule and dynein-binding chain and p150glued were reduced in peri-plaque BACE1-positive dystrophic neurites, while dynamitin and kinesin heavy chain tended to accumulate in dystrophies and showed partial but limited co-localization with BACE1. These results together with evidence of microtubule disruption strongly suggest that axonal transport is impaired in dystrophic regions of peri-plaque axons. DAPI staining (blue) identified nuclei and autofluorescence of amyloid plaque cores (marked by asterisks). Scale bars $10 \mu \mathrm{m}(\mathbf{a}, \mathbf{b}, \mathbf{d})$ and $20 \mu \mathrm{m}(\mathbf{c})$

domain through its interactions with Arp1 and p150glued, respectively [5]. The increased dynamitin in peri-plaque dystrophies suggested that it may be trapped in either free form or in complexes with adaptor proteins and cargo, but lacking p150glued, dynamitin cannot be attached to dynein and transported with cargo back toward the soma. Disruption of microtubule networks in peri-plaque dystrophic neurites would also be predicted to have an effect on anterograde axonal transport by kinesins and cause kinesin mislocalization. Our immunofluorescence microscopy analysis showed that, similar to dynamitin, kinesin heavy chain accumulated in dystrophies surrounding plaques (Figs. 5d, S3, S4), supporting our hypothesis that peri-plaque presynaptic dystrophic neurites are deficient in microtubules and exhibit mis-localized microtubule motor proteins, conditions that would impair axonal transport. 

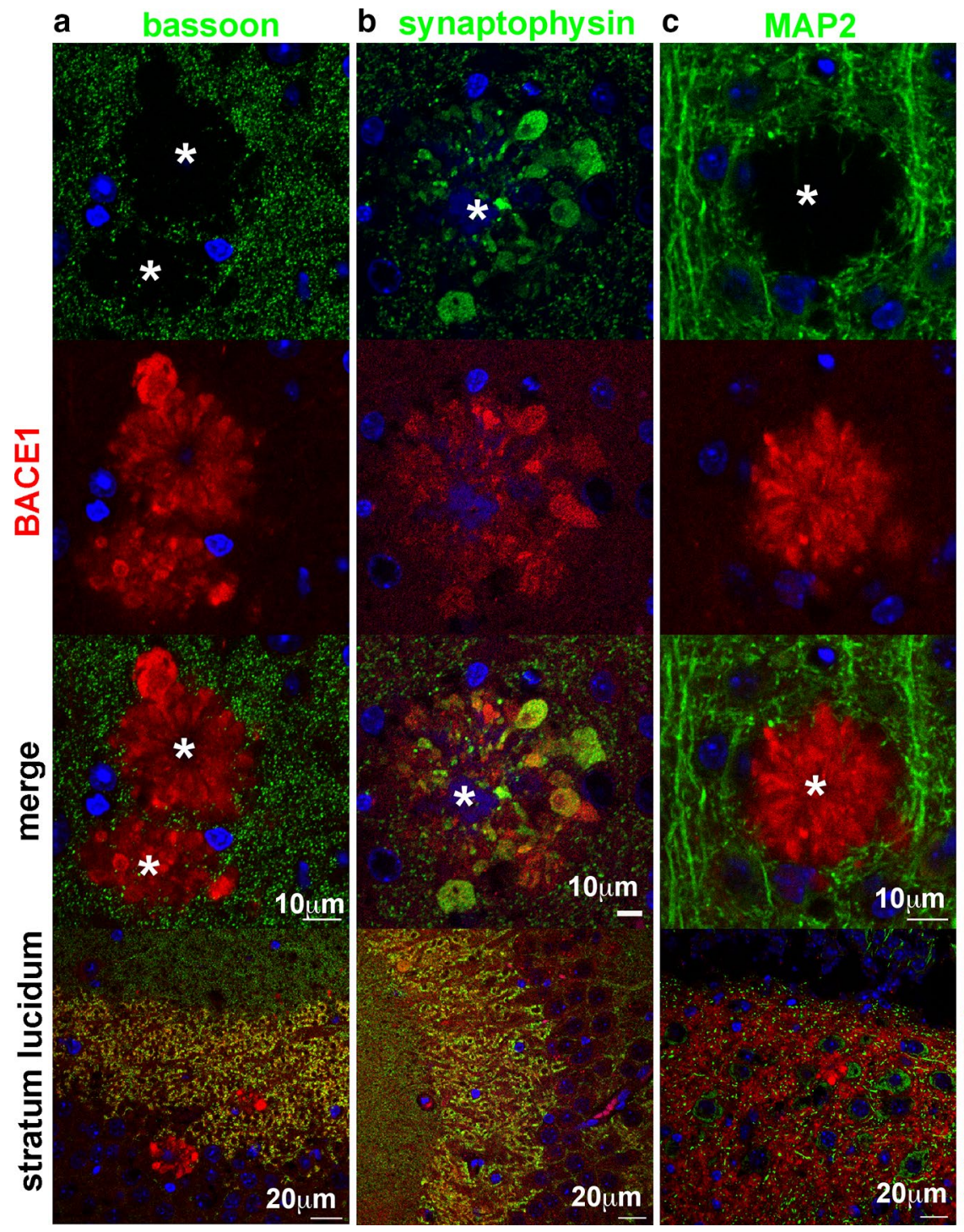

d cathepsinD

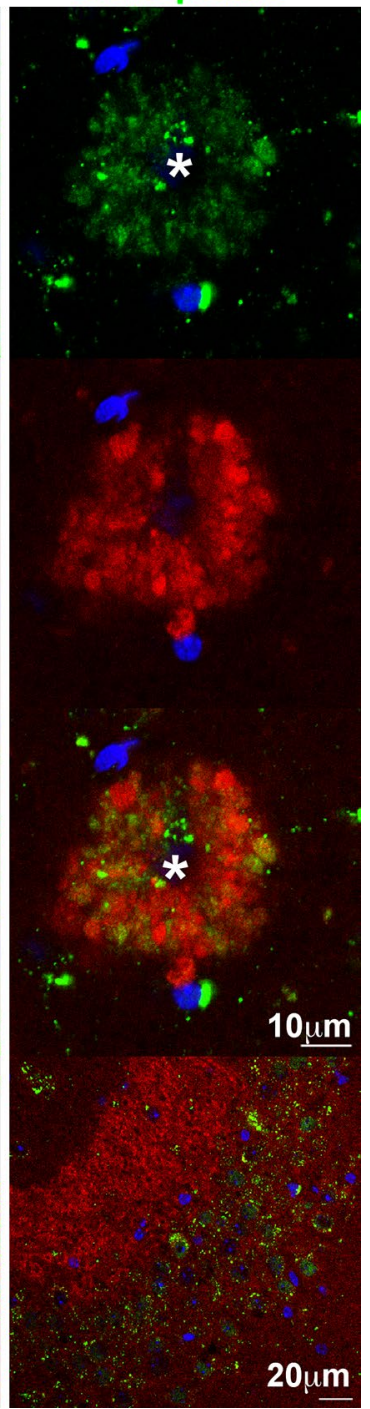

Fig. 6 BACE1-positive peri-plaque dystrophies accumulate the presynaptic protein synaptophysin and the lysosomal protease cathepsin $\mathrm{D}$, but lack the active zone protein bassoon. Sections from 5XFAD mouse brains were stained with antibodies against BACE1 (red) and active zone protein bassoon (green, a), presynaptic protein synaptophysin (green, b), somatodendritic marker MAP2, (green, c), or lysosomal protease cathepsin D (green, d). Representative amyloid deposits are shown; additional examples in Figs. S3 and S4. Both bassoon and synaptophysin co-localized extensively with BACE1 in presynaptic terminals in the stratum lucidum (bottom row), but bassoon and synaptophysin were absent and enriched in peri-plaque dystrophies, respectively (top row). The somatodendritic protein MAP2,

\section{BACE1-positive peri-plaque dystrophies are presynaptic, but lack components of functional synapses}

To further characterize BACE1-positive peri-plaque dystrophic neurites in 5XFAD brain sections, we performed immunofluorescence microscopy with antibodies which did not co-localize with BACE1 in the stratum lucidum (bottom row), was absent in peri-plaque dystrophies (top row). The lysosomal protease cathepsin D was found in neuronal soma as expected and did not co-localize with BACE1 in stratum lucidum (bottom row). However, cathepsin D tended to accumulate in some dystrophies, indicating aberrant localization of lysosomes in peri-plaque dystrophic neurites. These results suggest that BACE1-positive peri-plaque dystrophies are largely presynaptic axons and terminals, although dystrophic terminals are unlikely to have active synapses as they lack bassoon. DAPI staining (blue) identified nuclei and autofluorescence of amyloid plaque cores (marked by asterisks). Scale bars $10 \mu \mathrm{m}$ in all frames except for the bottom row, which is $20 \mu \mathrm{m}$

directed against BACE1 and several other neuronal proteins (Figs. 6, S3, S4), confirming that accumulation in dystrophies is specific to certain proteins but not others. Synaptophysin and bassoon, both presynaptic proteins, show strong co-localization with BACE1 in the stratum lucidum, the axon terminals of the mossy fiber pathway in the hippocampus (Fig. 6a, b; bottom row), confirming 

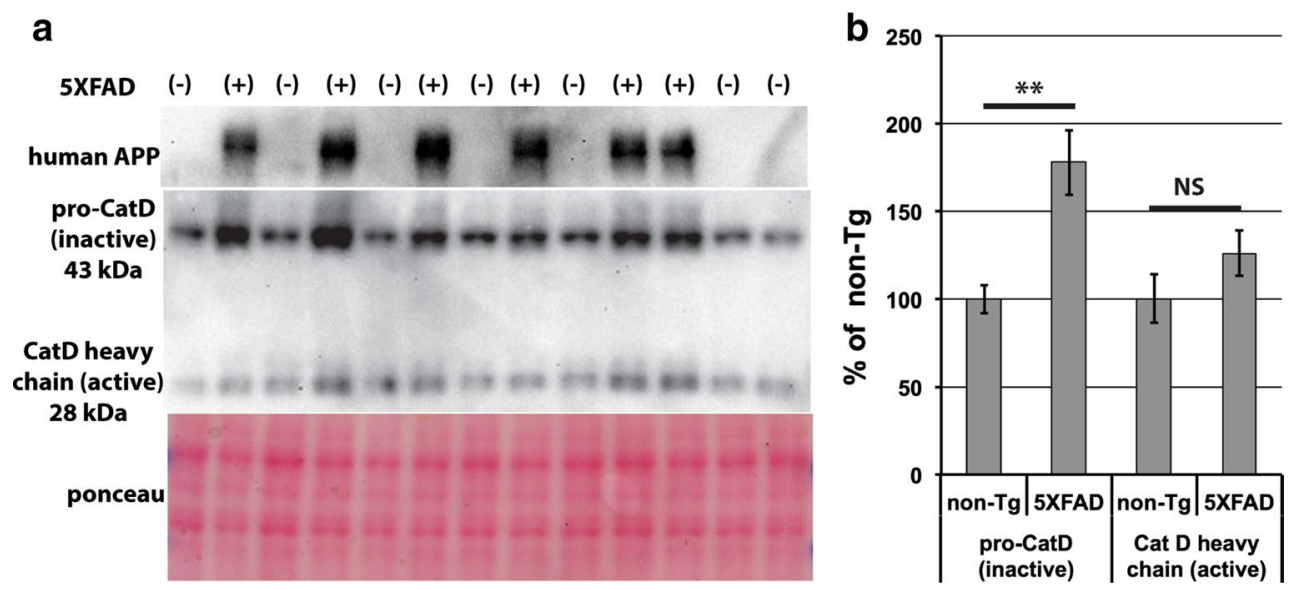

Fig. 7 Levels of immature pro-cathepsin D are increased in 5XFAD mouse brain. a Cortices from 6-month 5XFAD (+) or non-transgenic $(-)$ mice were homogenized and subjected to immunoblot analysis using antibodies against human APP (top panel; antibody 6E10) and the C-terminus of the lysosomal protease cathepsin D (CatD), which recognizes both immature (inactive) pro-CatD and mature (active) CatD heavy chain (middle panel). Ponceau S staining of the immunoblot was used to control for protein loading (bottom panel). Note that $43-\mathrm{kDa}$ immature pro-CatD bands are more intense than $28 \mathrm{kDa}$ mature CatD heavy chain bands, especially in 5XFAD cortices. b Band intensities from the immunoblot in a were quantified and normalized to total protein as determined by ponceau $\mathrm{S}$ staining intensity in respective lanes and then displayed as percentage of non-transgenic (non-Tg) control. Note that 5XFAD cortex levels of pro-CatD were nearly twofold higher than those in non-Tg cortex, while levels of CatD heavy chain were not significantly changed, suggesting that lysosomal maturation is impaired in 5XFAD brains. Error bars SEM; $* * p<0.01 ; N S$ not significant our previous results that BACE1 is normally localized in the presynaptic terminal [25]. As we have reported before $[25,86]$, and was recently confirmed $[15,50]$, many periplaque dystrophies appear to be axonal in origin, showing accumulations of the presynaptic protein synaptophysin (Fig. 6b), and a conspicuous absence of the somatodendritic marker MAP2 (Fig. 6c), which does not co-localize with BACE1 in the stratum lucidum (Fig. 6c; bottom panel). Surprisingly, given its strong co-staining with BACE1 in normal tissue of the stratum lucidum, bassoon appears to be entirely absent from peri-plaque dystrophies (Fig. 6a). Since bassoon is a well-established marker of synaptic active zones (reviewed in [6]), its absence from peri-plaque dystrophies indicates a lack of functional synapses in these regions. The toxic effect of amyloid plaques on synapses seems to be quite local, as the immunofluorescence signal for bassoon outside the immediate peri-plaque halo of the dystrophies appears as a normal punctate pattern. This is supported by other APP transgenic mouse studies showing that PSD95 was reduced by $60 \%$ in the halo of oligomeric $\mathrm{A} \beta 42$ surrounding plaques, while $50 \mu \mathrm{m}$ from the plaque it was found at normal levels [29].

\section{Immature pro-cathepsin D accumulates in 5XFAD mouse brain}

Cathepsin D is found in lysosomes, which normally localize to a peri-nuclear region of the soma rather than axon terminals, and cathepsin D does not co-localize with BACE1 in normal-appearing regions of the 5XFAD stratum lucidum (Fig. 6d, bottom panel). Although cathepsin $\mathrm{D}$ appeared somewhat elevated in 5XFAD BACE1-positive peri-plaque dystrophies, the patterns of cathepsin D and BACE1 localization did not overlap as extensively as those of synaptophysin and BACE1 (Figs. 6d, S3, S4). BACE1 is normally degraded through lysosomal pathways $[26,60]$, and thus presynaptic BACE1 is dependent on retrograde transport to the cell body for turnover. Early lysosomes, identified by Lamp1 expression, are found in dystrophic neurites $[15,25]$ but are deficient in cathepsins [15]. These studies together with our results suggest that microtubule disruption and motor protein mis-localization impair retrograde transport and hence lysosomal maturation, ultimately resulting in reduced degradation of BACE1 and other proteins in peri-plaque dystrophic neurites. The cathepsin D antibody that we used for our immunolocalization analysis (Fig. 6d) recognizes the C-terminus of both $43 \mathrm{kDa}$ pro-cathepsin $\mathrm{D}$ and $28 \mathrm{kDa}$ cathepsin D heavy chain, precluding our ability to determine whether peri-plaque cathepsin $\mathrm{D}$ was mature (active) or immature (inactive). To distinguish and quantify mature and immature forms of cathepsin $\mathrm{D}$, we performed immunoblot analysis of brain homogenates from 6-month-old 5XFAD and non-transgenic mice using the cathepsin D antibody (Fig. 7a). We observed that 5XFAD brains had significantly increased levels of immature pro-cathepsin D compared to brains of non-transgenic 

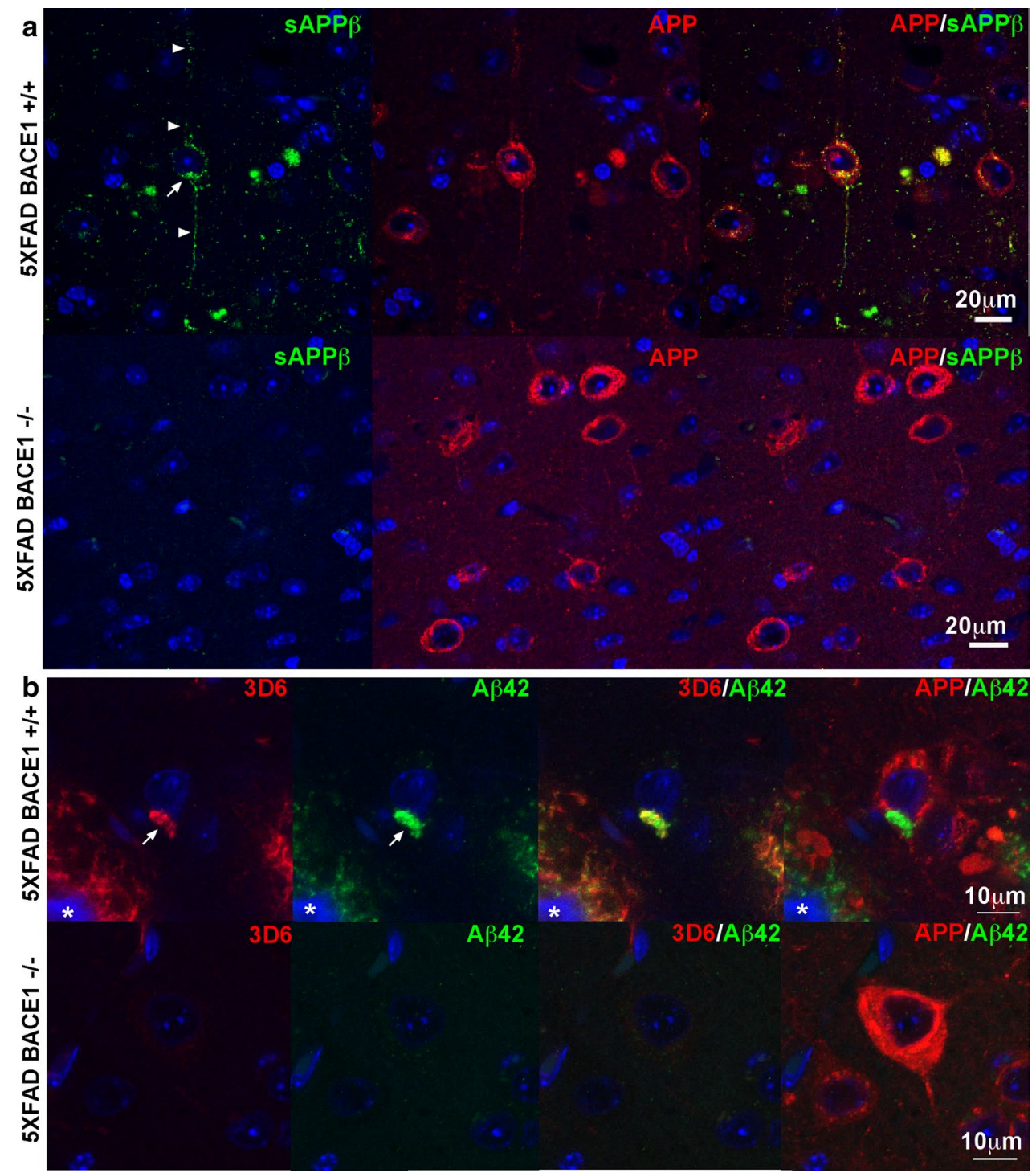

Fig. 8 Neoepitope antibodies recognize BACE1-cleaved APP and $A \beta$ but not full-length APP in vivo. Sagittal brain sections of 5XFAD;BACE1+/+ and 5XFAD;BACE1- $/-$ mice were immunostained with neoepitope antibodies to a the free C-terminus of BACE1-cleaved APP ectodomain ending in the Swedish mutation, sAPP $\beta$ (antibody ANJJ [45, 46], green), b the free N-terminus of BACE1-cleaved A $\beta$ (antibody 3D6 [23], red), or $\mathbf{c}$ the free C-terminus of $\gamma$-secretase-cleaved A 442 (green). Sections were also coimmunostained with an antibody recognizing full-length APP (antibody Karen [64], red), then imaged by confocal microscopy. All three neoepitope immunoreactivities were present in soma (arrows), and

littermates, while 5XFAD levels of mature cathepsin D heavy chain were unchanged (Fig. 7b). This result is consistent with the notion of impaired maturation of lysosomes in the brains of 5XFAD mice, which might contribute to accumulation of BACE1 and other proteins in peri-plaque dystrophic neurites. processes in the case of sAPP $\beta$ (arrowheads), of pyramidal neurons in the cortex of 5XFAD;BACE1 $1+/+$ mice, while none were detected in 5XFAD;BACE1-/- cortex, despite overexpression of transgenic APP in pyramidal neurons of both genotypes. These data confirm that ANJJ, 3D6, and A $\beta 42$ antibodies are selective for their respective neoepitopes and do not cross-react to full-length APP. DAPI staining (blue) identified nuclei and autofluorescence of amyloid deposit cores (marked by asterisks). Note that amyloid deposits are completely lacking in 5XFAD;BACE1-/- cortex, as previously reported [41]. Scale bars $10 \mu \mathrm{m}$ (b), $20 \mu \mathrm{m}$ (a)

\section{BACE1-positive peri-plaque dystrophic neurites are sources of increased production of BACE1-cleaved APP fragments and $\mathrm{A} \beta 42$}

Our observations of BACE1 accumulation around plaques led us to the hypothesis that elevated levels of BACE1, APP 
$[25,86]$, and PS1 [81] found in peri-plaque dystrophic neurites would cause increased BACE1 processing of APP and $\mathrm{A} \beta$ production, thus exacerbating $\mathrm{AD}$ pathogenesis. However, direct evidence that elevated BACE1 cleaves APP and leads to increased $A \beta$ formation in dystrophic neurites has been lacking. To address this question, we made use of several antibodies specific to neoepitopes of APP-derived fragments revealed by BACE1 and $\gamma$-secretase processing. BACE1 cleavage of APP generates two products, the $\mathrm{N}$-terminal soluble APP ectodomain fragment, sAPP $\beta$, and the membrane bound $\mathrm{C}$-terminal fragment, $\mathrm{C} 99$. The antibody ANJJ [45] recognizes the free C-terminus of sAPP $\beta$ created by BACE1 processing of APP with the Swedish familial AD mutation [38], which is expressed in 5XFAD mice [40]. To validate ANJJ for tissue immunostaining and verify that it does not recognize unprocessed full-length APP, we co-stained sagittal brain sections from 9-monthold 5XFAD;BACE1+/+ and 5XFAD;BACE1-/- bigenic mice with ANJJ and an antibody to an N-terminal epitope of full-length APP [64] and performed immunofluorescence confocal microscopy (Fig. 8). We observed punctate sAPP $\beta$ immunoreactivity of ANJJ in the soma and processes of 5XFAD;BACE1+/+ large pyramidal neurons in the cortex (Figs. 8a, upper panels; S4), the primary cells that express the 5XFAD transgenes in the brain [40]. The punctate intracellular immunostaining pattern for $\mathrm{sAPP} \beta$ was expected, since BACE1 cleaves APP in endosomes $[45,66]$ to create the $\mathrm{SAPP} \beta$ neoepitope and release the soluble APP ectodomain into the endosome lumen for eventual secretion into the extracellular milieu. The immunoreactivity of full-length APP exhibited a wider spatial distribution in the neuron compared to that of $\mathrm{sAPP} \beta$, indicating cell surface localization in addition to intracellular labeling. In contrast, sAPP $\beta$ immunosignal was completely absent in 5XFAD;BACE1-/- brain sections (Fig. 8a, lower panels), indicating the absence of the $\mathrm{SAPP} \beta$ free C-terminal neoepitope as expected for BACE1-deficient mice [34], even though full-length APP immunoreactivity throughout the neuron was similar to that observed in 5XFAD;BACE $1+/+$ sections. These results demonstrate conclusively that the ANJJ antibody only recognizes the BACE1-cleaved sAPP $\beta$ C-terminal neoepitope and does not cross-react to full-length APP in brain sections.

We also performed immunofluorescence microscopy on 5XFAD;BACE $1+/+$ and 5XFAD;BACE $1-/-$ brain sections incubated with antibodies recognizing neoepitopes on the free N-terminus of BACE1-cleaved A $\beta$ (3D6) [23] and the free $\mathrm{C}$-terminus of $\gamma$-secretase-cleaved $\mathrm{A} \beta$ ending in amino acid 42 (A $\beta 42)$, co-stained with the fulllength APP antibody (Fig. 8b). As with sAPP $\beta$ immunosignal, we observed intraneuronal 3D6 and $\mathrm{A} \beta 42$ neoepitope immunostaining only in large pyramidal cortical neurons of $5 \mathrm{XFAD}$;BACE $1+/+$ mice, while those of
5XFAD;BACE1 -/- mice were completely devoid of either 3D6 or A $\beta 42$ neoepitope immunoreactivities (Fig. 8b) even though they showed robust full-length APP labeling. Taken together, these results fully validate the 3D6 and A $\beta 42$ neoepitope antibodies for tissue immunostaining and confirm that they do not label full-length APP.

Next, using our validated neoepitope antibodies we sought to determine whether elevated BACE1 in periplaque dystrophies was associated with increased BACE1 processing of APP and A $\beta$ generation. Importantly, sagittal brain sections from 5- to 6-month and 9-month-old 5XFAD mice co-incubated with $\mathrm{SAPP} \beta$ neoepitope and BACE1 antibodies showed robust punctate $\mathrm{SAPP} \beta$ immunoreactivity, likely representing endosomal localization, within peri-plaque dystrophies that significantly co-localized with BACE1 immunosignal (Figs. 9a, S4). sAPP $\beta$ immunoreactivity was very intense in peri-plaque dystrophies, compared to the very low sAPP $\beta$ immunosignal in the surrounding neuropil, indicating that BACE1 processing of APP was dramatically increased in the BACE1-positive dystrophic neurites near amyloid deposits. We noted that peri-plaque dystrophies exhibited variable levels of transgenic sAPP $\beta$ immunoreactivity, presumably because the Thy 1 transgene promoter is expressed in some, but not all, cortical neurons [36]. Similar to the sAPP $\beta$ immunostaining pattern, we observed increased punctate 3D6 and $A \beta 42$ neoepitope immunosignals that co-localized significantly with BACE1 immunoreactivity in peri-plaque dystrophies (Figs. 9b, c, respectively; S4), suggesting that BACE1 accumulation elevated $A \beta$ production. Although 3D6 and $A \beta 42$ immunosignal intensities in dystrophies were weaker than those in amyloid deposits, they were obviously elevated compared to surrounding neuropil, especially at higher magnifications (right panels, 9b, c). Additionally, sAPP $\beta$ and 3D6 neoepitope immunoreactivities co-localized significantly in peri-plaque dystrophies (Fig. 9d). Co-immunostaining of 5XFAD brain sections with full-length APP and BACE1 antibodies confirmed that APP and BACE1 accumulate together in peri-plaque dystrophies (Fig. 9e), implicating both in plaque progression.

Taken together, our results suggest that elevated BACE1 in dystrophic neurites around plaques is associated with increased BACE1 cleavage of APP and A $\beta$ generation. The presence of neoepitope $\mathrm{N}$-terminal and $\mathrm{C}$-terminal APP processing products in peri-plaque dystrophies strongly supports the hypothesis that BACE1 and $\gamma$-secretase are active in dystrophies, although we cannot formally exclude the possibility that APP processing occurs elsewhere in the cell followed by APP product trafficking and accumulation in dystrophies. Additionally, our results show that peri-plaque dystrophic neurites accumulate $\mathrm{A} \beta 42$, which if released into the extracellular space could contribute to plaque growth and further neuritic dystrophy. 

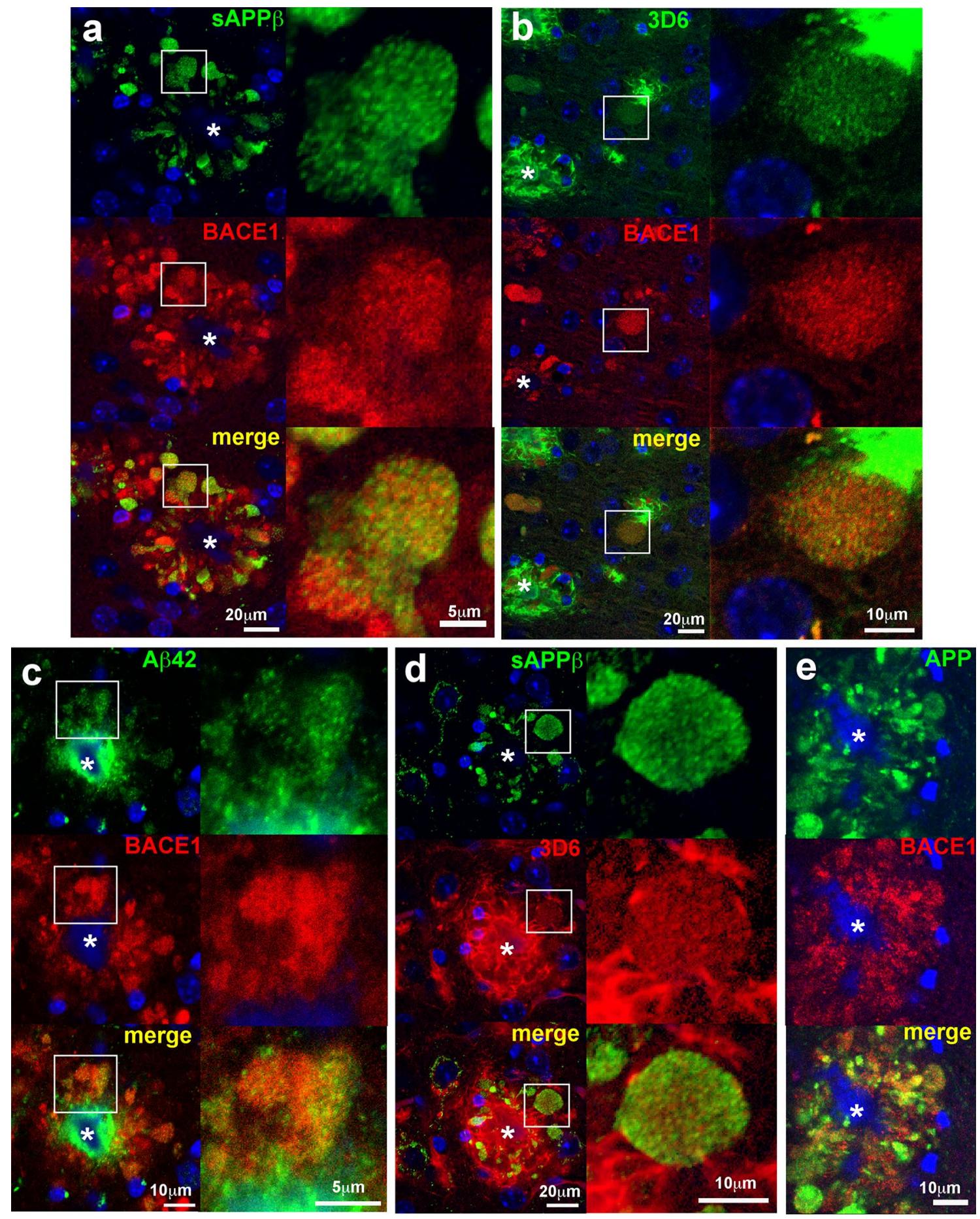

\section{Discussion}

In this study, we provide evidence that $\mathrm{A} \beta$ mediates microtubule disruption and microtubule-based transport impairment leading to dystrophic neurite formation, BACE1 accumulation, increased BACE1 cleavage of APP and A $\beta$ production. Primary neurons treated with $A \beta 42$ oligomers exhibited disrupted microtubules, neuritic beading, and reduced BACE1-YFP trafficking after only a short $\mathrm{A} \beta 42$ exposure in vitro. In the 5XFAD mouse model of amyloid pathology, presynaptic dystrophic neurites surrounding plaques showed BACE1 accumulation that correlated with aberrant localization patterns of tubulins, microtubule motor proteins, and synaptic and cell body proteins. Tubulin was largely absent from human AD and 5XFAD BACE1-positive peri-plaque dystrophies and showed 
4 Fig. 9 BACE1 accumulation in peri-plaque dystrophic neurites increases BACE1 cleavage of APP and generation of A $\beta 42$. Sagittal brain sections of 5XFAD mice were co-immunostained with antibodies recognizing BACE1 and cleaved APP fragment neoepitopes (sAPP $\beta, 3 \mathrm{D} 6, \mathrm{~A} \beta 42$ ) validated in Fig. 8. a The BACE1-cleaved free C-terminal neoepitope of SAPP $\beta$ (ANJJ, green) showed robust colocalization with elevated BACE1 (red) in peri-plaque dystrophic neurites. Note the intense sAPP $\beta$ immunoreactivity in dystrophies, while little if any sAPP $\beta$ signal is present in surrounding neuropil, demonstrating dramatically elevated BACE1 cleavage of APP in BACE1-positive dystrophic neurites near amyloid deposits. b Antibody 3D6 (green), which recognizes the free N-terminal neoepitope of BACE1-cleaved A $\beta$, also co-localized with elevated BACE1 (red) in dystrophic neurites, confirming increased BACE1 activity and $\mathrm{A} \beta$ generation in dystrophies. Antibody 3D6 also detects amyloid plaques, as expected (example marked with asterisk). c Like 3D6, an antibody recognizing the free $\mathrm{C}$-terminal neoepitope generated after $\gamma$-secretase cleavage of A $\beta 42$ (green) co-localized with elevated BACE1 (red) in peri-plaque dystrophies, and detected amyloid deposits, as expected (asterisk). d Co-immunostaining also demonstrated that both sAPP $\beta$ (green) and 3D6 (A $\beta$, red) neoepitopes colocalized in peri-plaque dystrophies. e Co-immunostaining with antibodies against BACE1 (red) and APP (Karen, green) also showed a high level of co-localization. Note that all cleaved APP fragment neoepitopes and BACE1 show a punctate immunostaining pattern in dystrophies, suggesting that they are localized to vesicles such as endosomes, while APP immunostaining appears more uniform, implying greater cell surface localization. Panels in the right column of each set are high-magnification images of the boxed regions in the frames of the left column. DAPI staining (blue) identified nuclei and autofluorescence of amyloid deposit cores (marked by asterisks). Scale bar sizes are indicated in bottom panels for images in each column

increased BACE1:tubulin ratios and inverse relationships between BACE1 and tubulin. Although 5XFAD peri-plaque dystrophic neurites accumulated the lysosomal protease cathepsin D, it largely appeared to be immature pro-cathepsin $\mathrm{D}$, suggesting that impaired lysosomal maturation correlates with BACE1 accumulation. By EM, peri-plaque dystrophic axons lacked intact microtubules, consistent with reduced tubulin by immunofluorescence microscopy. Remarkably, the toxic effects of amyloid on dystrophies were highly localized to the immediate vicinity of the plaque, with neighboring axons and terminals appearing normal. Multi-photon confocal microscopy 3D-reconstructions of live 5XFAD;BACE1-YFP brain slices invariably showed physical contact between BACE1-YFP-positive dystrophies and amyloid deposits. Most importantly, periplaque dystrophies displayed BACE1 and APP accumulation, increased BACE1 cleavage of APP, and elevated A $\beta 42$ generation.

Taken together, our results suggest the following working hypothesis of presynaptic dystrophic neurite formation and plaque progression (Fig. S6). During early stages of amyloid deposition, a plaque nidus forms stochastically in the parenchyma and is too small to be significantly toxic to axons and terminals. Following further $\mathrm{A} \beta$ addition, the plaque grows large enough to come into close proximity to a nearby axon or terminal and causes neurotoxicity derived from high local concentrations of either soluble $A \beta$ oligomers or insoluble $A \beta$ fibrils. An as yet undefined cascade is triggered that leads to local destabilization and/or depolymerization of microtubules in the axon; microtubules in more distant regions of the axon are unaffected. Microtubuledependent axonal transport is impaired locally in the region of the axon nearest the plaque in which microtubules are disrupted, although transport is normal in segments further away from the plaque. Vesicles proximal and distal to the plaque undergoing anterograde and retrograde transport, respectively, detach from the ends of disrupted microtubules and begin to accumulate causing swelling and axonal dystrophy nearest the plaque. The accumulation of vesicles containing APP, BACE1, and $\gamma$-secretase leads to increased APP processing and $A \beta$ generation in the dystrophic region of the axon and may accelerate growth and development of the nearby plaque. This in turn results in a feed-forward mechanism of increased axonal dystrophy, BACE1 and APP accumulation, and $A \beta$ generation. Together with dysfunction associated with axonal swelling and impaired transport, this cascade is likely to exacerbate downstream neurodegeneration leading to cognitive deficits. Despite being likely of presynaptic origin, peri-plaque dystrophies lack a structural protein of active zones, bassoon, suggesting that they are not functional in synaptic transmission. Importantly, this cascade would disrupt vesicular trafficking from the soma to the terminal and vice versa. Protein turnover could be inhibited resulting in accumulation of certain proteins like BACE1, and loss of others according to the specific cellular mechanisms by which their transport and degradation are controlled. In future work, it will be important to determine the potential roles of other major players in dystrophic neurite generation, such as Reticulon 3 , which has been implicated in dystrophic neurite formation $[19,52,53]$, or the recently discovered $\eta$-secretase processing of APP [73] (see Supplementary Text, Fig. S7), in the processes that we describe here.

Our data suggest that BACE1-positive peri-plaque dystrophic neurites are axonal or terminal in origin due to the presence of the predominantly axonal protein neurofilament NF-M [25, 74], synaptic vesicle protein synaptophysin (Fig. 6b) $[25,85,86]$ and myelination (Fig. 4), and absence of the somatodendritic protein MAP2 (Fig. 6c) [25, 85, 86]. Moreover, endogenous BACE1 is highly concentrated in vesicles of presynaptic terminals [25]. Consistent with our results, other APP transgenic mice have peri-plaque APP-positive dystrophies that stain for synaptophysin and the presynaptic vesicular glutamate transporter VGLUT1 but lack MAP2, and also have dystrophies that are myelinated and accumulate autophagic intermediates by EM [50]. VGLUT1 and other presynaptic markers including growth-associated protein 43 (GAP43), glutamic acid 
decarboxylase 67 (GAD67), and choline acetyltransferase (ChAT) have also been shown to co-localize with BACE1 in dystrophic neurites, supporting their presynaptic/axonal origin [85]. Although lack of BACE1 and MAP2 co-localization does not guarantee that BACE1-positive dystrophies are not dendritic, the robust co-localization of BACE1 with five presynaptic markers strongly suggests presynaptic origin. The absence of synaptic active zone scaffold protein bassoon in BACE1-positive dystrophies (Fig. 6a) could be caused by loss of normal synaptic structure. The post-synaptic density protein PSD95 is also reduced around plaques [29], supporting this hypothesis. Thus, the majority of evidence suggests that BACE1-positive peri-plaque dystrophies are presynaptic in origin, although we cannot exclude the possibility that some BACE1-positive dystrophic neurites are post-synaptic/dendritic in nature.

There has been much debate about whether plaques are a toxic agent in Alzheimer's disease, or a mechanism for the brain to sequester amyloid in a less harmful form. Early reports indicated that plaque load did not correlate well with cognitive impairment [1, 59]. However, recent work has shown that cerebral amyloid deposition identified by amyloid-PET imaging in cognitively normal and mildly impaired individuals predicts conversion to AD [22]. Furthermore, numerous studies have documented toxic effects such as mitochondrial loss [77], oxidative damage [78], synapse loss [29], and spine loss [75] in the immediate vicinity of plaques. In our study, we found that dystrophic neurites appear to be in contact with amyloid plaques at the ultrastructural level (Fig. 4), by immunofluorescence microscopy (Figs. 3, 5, 6, 9, S3, S4) and in live slices by multi-photon confocal microscopy (Fig. S5; Videos S1, S2), whereas areas of neuropil slightly further away are morphologically normal. Interestingly, a study using an antibody specific to oligomeric $\mathrm{A} \beta$ (NAB61) determined that a halo of oligomeric $\mathrm{A} \beta$ extends $\sim 6.5 \mu \mathrm{m}$ beyond the edge of the fibrillar $A \beta$ core [29]. These results suggest that plaques are sources of soluble $\mathrm{A} \beta$ oligomers, widely thought to be the toxic species in $\mathrm{AD}$, that are in dynamic equilibrium with insoluble $A \beta$ deposits, thus creating high local concentrations of neurotoxic $\mathrm{A} \beta$.

Previous studies have reported that soluble $A \beta$ levels in the brain are in the picomolar range $[33,76]$. However, this estimate is based on biochemical isolation of $A \beta$ from postmortem brain lysates and thus is the average concentration of soluble $A \beta$ in the brain, but it may not reflect the local soluble $A \beta$ concentration near the plaque. To our knowledge, absolute soluble $A \beta$ concentrations in the immediate vicinity of the plaque have not been quantified. Although a halo of $\mathrm{A} \beta$ oligomers emanating from individual plaques has been demonstrated [29], the absolute quantification of soluble peri-plaque $A \beta$ concentrations was not performed in this study. Thus, we suggest that local peri-plaque concentrations of soluble $\mathrm{A} \beta$ may be much higher than average $\mathrm{A} \beta$ concentrations in the brain. If so, high local soluble $A \beta$ concentrations may cause microtubule disruption and neuritic swelling in the portion of the neurite that is very near the plaque, but parts of the neurite that are farther away would be exposed to lower soluble $\mathrm{A} \beta$ concentrations that may not induce neuritic dystrophy. Such a localized effect on only the peri-plaque portion of the neurite may not induce cell death processes in the distant cell body, at least not initially. This scenario is consistent with both our in vitro and in vivo results.

Although it is challenging to measure $A \beta$ oligomer concentrations in the halo surrounding the amyloid deposit, the local concentrations of $A \beta$ may reach very high values approaching the plaque. We used relatively high concentrations of $A \beta 42$ oligomers $(1-10 \mu \mathrm{M})$ in our primary neuron experiments to model the high local oligomeric $A \beta 42$ concentration in the immediate vicinity of the amyloid deposit. It is unlikely that microtubule disruption (Figs. 1,2) and axonal transport impairment (Fig. S2) in A $\beta 42$-treated primary neurons were the result of cell death processes, since propidium iodide staining showed no increase in dead cells in the A $\beta 42$-treated cultures (Fig. S1). Additionally, we previously showed that 5 days of treatment with 1 or $2 \mu \mathrm{M}$ A $\beta 42$ oligomers caused no significant increase of activated caspase 3 in primary neurons [49]. Microtubule disruption may occur at concentrations lower than $1 \mu \mathrm{M}$ $\mathrm{A} \beta 42$, although we have not tested this yet. However, a previous study has shown that $0.5 \mu \mathrm{M} \mathrm{A} \beta 42$ oligomers does not appear to disrupt microtubules in primary neurons [7], suggesting that $1 \mu \mathrm{M} \mathrm{A \beta 42} \mathrm{may} \mathrm{be} \mathrm{a} \mathrm{threshold} \mathrm{concentra-}$ tion for microtubule disruption. The relationship between our in vitro and in vivo results still requires further investigation, but even in aged 5XFAD mice with high levels of soluble $\mathrm{A} \beta 42$, we observe microtubule disruption and aberrant tubulin localization only in the immediate vicinity of amyloid deposits, suggesting that high $\mathrm{A} \beta 42$ concentrations are necessary for these effects. When conditional expression of APP in transgenic mouse brain is reduced by over $90 \%$ with doxycycline treatment, $A \beta 40$ and $A \beta 42$ levels in interstitial fluid drop by about $70 \%$, suggesting that while plaques are fairly stable over time, they do contribute to soluble $\mathrm{A} \beta$ in the brain [13]. The hypothesis has been advanced that the toxic species of $A \beta$ is generated in plaques, as the $A \beta$ bound there over time becomes modified, gaining neurotoxicity [83]. Alternatively, insoluble fibrillar $A \beta$ in plaques could be directly neurotoxic, or indirectly induce toxicity through secondary mechanisms such as neuroinflammation. Much future research remains to precisely define the exact neurotoxic species of $A \beta$ in $A D$.

The cellular and molecular mechanisms leading to amyloid-induced microtubule disruption and axonal dystrophy are not yet clear. Recent studies investigating the effects 
of $A \beta 42$ oligomers on Tau mis-sorting indicate that the microtubule-severing enzyme spastin mediates microtubule breakdown in dendrites [82]; however, a role for this mechanism in axons is unclear. It is unlikely that Tau is directly involved in the generation of dystrophic neurites, as hAPP; Tau-/- mice have the same plaque area and same percentage of plaques with dystrophic neurites as hAPP; Tau+/+ mice despite having improved survival and cognitive function [47]. Importantly, the absence of Tau did not affect the generation of APP-positive dystrophies that, based upon our results, were also likely BACE1-positive (Fig. 9e). These results suggest that Tau has an important role in A $\beta$-related cognitive deficits, but Tau does not appear central to the effects of amyloid deposits on dystrophic neurite formation. It is more likely that depolymerization of microtubules affects Tau phosphorylation, mis-sorting, and aggregation.

A $\beta 42$ oligomers have been proposed to mediate toxicity through a number of extracellular receptors such as glutamate receptors, p75 neurotrophin receptors, nicotinic acetylcholine receptors, amylin receptors, the receptor for advanced glycation end products (RAGE), insulin and IGF receptors, and others (reviewed in [42]). Activation of these receptors leads to changes in LTP, modulation of various signaling cascades, including Jun kinase, p38, MAPKs and p53, as well as caspase activation (reviewed in [42]), some of which can cause apoptosis and cell death. Oligomeric A $\beta 42$ leads to synaptic dysfunction that correlates with cognitive decline, perhaps mediated through effects on NMDA receptors [63]. One study showed that NMDA receptor antagonists and GSK3 $\beta$ inhibitors prevented $A \beta$ oligomer-induced disruption of axonal trafficking, suggesting that these pathways are involved [7].

The identity of BACE1-positive vesicles in peri-plaque dystrophic axons is not yet clear. Our previous EM analysis indicates that the dystrophies are heterogeneous, some containing smaller, clear vesicles, possibly endosomes, and others containing larger, multi-lamellar, electron-dense vesicles that may be autophagic/lysosomal intermediates [25]. By immuno-EM, BACE1 is predominantly found in dystrophies with small, electron-translucent vesicles. Recent work indicates that large numbers of Lamp1-positive immature lysosomes accumulate around plaques, and that BACE1 co-localizes with Lamp1, suggesting BACE1 accumulation in immature lysosomes [15]. Although we have observed Lamp1 [25] and cathepsin D (this study) accumulation in peri-plaque dystrophies, co-localization of these lysosomal proteins with BACE1 is limited, suggesting that BACE1 trafficking to lysosomes is impaired. Additionally, our data showing elevated immature proteolytically inactive pro-cathepsin D in 5XFAD brains support the hypothesis that lysosomal maturation is impaired, which could reduce the degradation of BACE1 and cause it to accumulate. Further studies are needed to better characterize the heterogeneity of peri-plaque dystrophies, and determine its causes and consequences.

While we clearly observed A $\beta 42$ in presynaptic dystrophic neurites around plaques, future investigation must determine whether these dystrophies are a significant source of $A \beta 42$ for plaque growth. Local $A \beta$ generation should be higher in plaque-rich than in plaque-poor brain regions, and in older APP transgenic mice with elevated BACE1, compared to young animals. If so, these data could indicate that stabilization of microtubules might be beneficial in slowing pathology and plaque growth, and perhaps preserve neuronal and cognitive function for the treatment of AD.

Acknowledgments The authors would like to thank Lawrence Rajendran and Patrick Keller for the generous gift of the anti-sAPP $\beta$ Swedish antibody (ANJJ), Virginia Lee for the anti-APP antibody (Karen), Lisa McConlogue for anti-A $\beta$ antibody (3D6), and Lester Binder for the anti- $\beta$ III tubulin antibody (TuJ1). We would also like to thank Lawrence Rajendran for thoughtful comments on the manuscript and Eileen H. Bigio in the Cognitive Neurology and Alzheimer's Disease Center at Northwestern University (funded by NIH R01 AG13854) for human post-mortem brain tissue. Imaging work was performed at the Northwestern University Center for Advanced Microscopy generously supported by NCI CCSG P30 CA060553 awarded to the Robert H Lurie Comprehensive Cancer Center. Spinning disk confocal microscopy was performed on an Andor XDI Revolution microscope, purchased through the support of NCRR 1S10 RR031680-01. Multi-photon microscopy was performed on a Nikon A1R multi-photon microscope, acquired through the support of NIH 1S10OD010398-01. This work was supported by NIH R01 AG030142, the Cure Alzheimer's Fund, and the Baila Foundation to RV, NIH R01 AG019070 and the Cure Alzheimer's Fund to GT, BrightFocus Foundation to VB-P, and NIH T32-070715 to PCK.

Open Access This article is distributed under the terms of the Creative Commons Attribution 4.0 International License (http://creativecommons.org/licenses/by/4.0/), which permits unrestricted use, distribution, and reproduction in any medium, provided you give appropriate credit to the original author(s) and the source, provide a link to the Creative Commons license, and indicate if changes were made.

\section{References}

1. Arriagada PV, Growdon JH, Hedley-Whyte ET, Hyman BT (1992) Neurofibrillary tangles but not senile plaques parallel duration and severity of Alzheimer's disease. Neurology 42:631-639

2. Blasko I, Beer R, Bigl M, Apelt J, Franz G, Rudzki D, Ransmayr G, Kampfl A, Schliebs R (2004) Experimental traumatic brain injury in rats stimulates the expression, production and activity of Alzheimer's disease beta-secretase (BACE-1). J Neural Transm 111:523-536

3. Boissonneault V, Plante I, Rivest S, Provost P (2009) MicroRNA-298 and microRNA-328 regulate expression of mouse beta-amyloid precursor protein-converting enzyme 1. J Biol Chem 284:1971-1981

4. Cai $\mathrm{H}$, Wang $\mathrm{Y}$, McCarthy $\mathrm{D}$, Wen $\mathrm{H}$, Borchelt DR, Price DL, Wong PC (2001) BACE1 is the major beta-secretase for 
generation of Abeta peptides by neurons. Nat Neurosci 4:233234. doi:10.1038/85064

5. Cheong FK, Feng L, Sarkeshik A, Yates JR 3rd, Schroer TA (2014) Dynactin integrity depends upon direct binding of dynamitin to Arp1. Mol Biol Cell 25:2171-2180. doi:10.1091/mbc. E14-03-0842

6. Clarke GL, Chen J, Nishimune H (2012) Presynaptic active zone density during development and synaptic plasticity. Front Mol Neurosci 5:12. doi:10.3389/fnmol.2012.00012

7. Decker H, Lo KY, Unger SM, Ferreira ST, Silverman MA (2010) Amyloid-beta peptide oligomers disrupt axonal transport through an NMDA receptor-dependent mechanism that is mediated by glycogen synthase kinase 3 beta in primary cultured hippocampal neurons. J Neurosci 30:9166-9171. doi:10.1523/ JNEUROSCI.1074-10.2010

8. Di Fede G, Catania M, Morbin M, Rossi G, Suardi S, Mazzoleni G, Merlin M, Giovagnoli AR, Prioni S, Erbetta A, Falcone C, Gobbi M, Colombo L, Bastone A, Beeg M, Manzoni C, Francescucci B, Spagnoli A, Cantu L, Del Favero E, Levy E, Salmona M, Tagliavini F (2009) A recessive mutation in the APP gene with dominant-negative effect on amyloidogenesis. Science 323:1473-1477. doi:10.1126/science.1168979

9. Dickson DW (1997) The pathogenesis of senile plaques. J Neuropathol Exp Neurol 56:321-339

10. Emery DG, Lucas JH (1995) Ultrastructural damage and neuritic beading in cold-stressed spinal neurons with comparisons to NMDA and A23187 toxicity. Brain Res 692:161-173

11. Evans NA, Facci L, Owen DE, Soden PE, Burbidge SA, Prinjha RK, Richardson JC, Skaper SD (2008) Abeta(1-42) reduces synapse number and inhibits neurite outgrowth in primary cortical and hippocampal neurons: a quantitative analysis. J Neurosci Methods 175:96-103. doi:10.1016/j.jneumeth.2008.08.001

12. Faghihi MA, Zhang M, Huang J, Modarresi F, Van der Brug MP, Nalls MA, Cookson MR, St-Laurent G 3rd, Wahlestedt C (2010) Evidence for natural antisense transcript-mediated inhibition of microRNA function. Genome Biol 11:R56

13. Fowler SW, Chiang AC, Savjani RR, Larson ME, Sherman MA, Schuler DR, Cirrito JR, Lesne SE, Jankowsky JL (2014) Genetic modulation of soluble Abeta rescues cognitive and synaptic impairment in a mouse model of Alzheimer's disease. J Neurosci 34:7871-7885. doi:10.1523/JNEUROSCI.0572-14.2014

14. Fukumoto H, Cheung BS, Hyman BT, Irizarry MC (2002) Betasecretase protein and activity are increased in the neocortex in Alzheimer disease. Arch Neurol 59:1381-1389

15. Gowrishankar S, Yuan P, Wu Y, Schrag M, Paradise S, Grutzendler J, De Camilli P, Ferguson SM (2015) Massive accumulation of luminal protease-deficient axonal lysosomes at Alzheimer's disease amyloid plaques. Proc Natl Acad Sci USA. doi:10.1073/ pnas. 1510329112

16. Haass C, Selkoe DJ (2007) Soluble protein oligomers in neurodegeneration: lessons from the Alzheimer's amyloid betapeptide. Nat Rev Mol Cell Biol 8:101-112. doi:10.1038/ nrm2101

17. Hebert SS, Horre K, Nicolai L, Papadopoulou AS, Mandemakers W, Silahtaroglu AN, Kauppinen S, Delacourte A, De Strooper B (2008) Loss of microRNA cluster miR-29a/b-1 in sporadic Alzheimer's disease correlates with increased BACE1/beta-secretase expression. Proc Natl Acad Sci USA 105:6415-6420

18. Holsinger RMD, McLean CA, Beyreuther K, Masters CL, Evin $\mathrm{G}$ (2002) Increased expression of the amyloid precursor betasecretase in Alzheimer's disease. Ann Neurol 51:783-786

19. Hu X, Shi Q, Zhou X, He W, Yi H, Yin X, Gearing M, Levey A, Yan R (2007) Transgenic mice overexpressing reticulon 3 develop neuritic abnormalities. EMBO J 26:2755-2767. doi:10.1038/sj.emboj.7601707
20. Hussain I, Powell D, Howlett DR, Tew DG, Meek TD, Chapman C, Gloger IS, Murphy KE, Southan CD, Ryan DM, Smith TS, Simmons DL, Walsh FS, Dingwall C, Christie G (1999) Identification of a novel aspartic protease (Asp 2) as beta-secretase. Mol Cell Neurosci 14:419-427. doi:10.1006/mcne.1999.0811

21. Ikegami K, Kato S, Koike T (2004) $N$-alpha-p-tosyl-L-lysine chloromethyl ketone (TLCK) suppresses neuritic degeneration caused by different experimental paradigms including in vitro Wallerian degeneration. Brain Res 1030:81-93. doi:10.1016/j. brainres.2004.09.050

22. Jack CR Jr, Barrio JR, Kepe V (2013) Cerebral amyloid PET imaging in Alzheimer's disease. Acta Neuropathol 126:643-657. doi:10.1007/s00401-013-1185-7

23. Johnson-Wood K, Lee M, Motter R, Hu K, Gordon G, Barbour R, Khan K, Gordon M, Tan H, Games D, Lieberburg I, Schenk D, Seubert P, McConlogue L (1997) Amyloid precursor protein processing and A beta42 deposition in a transgenic mouse model of Alzheimer disease. Proc Natl Acad Sci USA 94:1550-1555

24. Jonsson T, Atwal JK, Steinberg S, Snaedal J, Jonsson PV, Bjornsson S, Stefansson H, Sulem P, Gudbjartsson D, Maloney J, Hoyte K, Gustafson A, Liu Y, Lu Y, Bhangale T, Graham RR, Huttenlocher J, Bjornsdottir G, Andreassen OA, Jonsson EG, Palotie A, Behrens TW, Magnusson OT, Kong A, Thorsteinsdottir U, Watts RJ, Stefansson K (2012) A mutation in APP protects against Alzheimer's disease and age-related cognitive decline. Nature 488:96-99. doi:10.1038/nature11283

25. Kandalepas PC, Sadleir KR, Eimer WA, Zhao J, Nicholson DA, Vassar R (2013) The Alzheimer's beta-secretase BACE1 localizes to normal presynaptic terminals and to dystrophic presynaptic terminals surrounding amyloid plaques. Acta Neuropathol 126:329-352. doi:10.1007/s00401-013-1152-3

26. Kang EL, Cameron AN, Piazza F, Walker KR, Tesco G (2010) Ubiquitin regulates GGA3-mediated degradation of BACE1. J Biol Chem 285:24108-24119

27. Kardon JR, Reck-Peterson SL, Vale RD (2009) Regulation of the processivity and intracellular localization of Saccharomyces cerevisiae dynein by dynactin. Proc Natl Acad Sci USA 106:56695674. doi:10.1073/pnas.0900976106

28. Kawataki T, Osafune K, Suzuki M, Koike T (2008) Neuronal maturation-associated resistance of neurite degeneration caused by trophic factor deprivation or microtubule-disrupting agents. Brain Res 1230:37-49. doi:10.1016/j.brainres.2008.06.075

29. Koffie RM, Meyer-Luehmann M, Hashimoto T, Adams KW, Mielke ML, Garcia-Alloza M, Micheva KD, Smith SJ, Kim ML, Lee VM, Hyman BT, Spires-Jones TL (2009) Oligomeric amyloid beta associates with postsynaptic densities and correlates with excitatory synapse loss near senile plaques. Proc Natl Acad Sci USA 106:4012-4017

30. Lazarus JE, Moughamian AJ, Tokito MK, Holzbaur EL (2013) Dynactin subunit p150(Glued) is a neuron-specific anti-catastrophe factor. PLoS Biol 11:e1001611. doi:10.1371/journal.pbio.1001611

31. Li R, Lindholm K, Yang LB, Yue X, Citron M, Yan R, Beach T, Sue L, Sabbagh M, Cai H, Wong P, Price D, Shen Y (2004) Amyloid beta peptide load is correlated with increased beta-secretase activity in sporadic Alzheimer's disease patients. Proc Natl Acad Sci USA 101:3632-3637

32. Lloyd TE, Machamer J, O'Hara K, Kim JH, Collins SE, Wong MY, Sahin B, Imlach W, Yang Y, Levitan ES, McCabe BD, Kolodkin AL (2012) The p150(Glued) CAP-Gly domain regulates initiation of retrograde transport at synaptic termini. Neuron 74:344-360. doi:10.1016/j.neuron.2012.02.026

33. Lue LF, Kuo YM, Roher AE, Brachova L, Shen Y, Sue L, Beach T, Kurth JH, Rydel RE, Rogers J (1999) Soluble amyloid beta peptide concentration as a predictor of synaptic change in Alzheimer's disease. Am J Pathol 155:853-862 
34. Luo Y, Bolon B, Kahn S, Bennett BD, Babu-Khan S, Denis P, Fan W, Kha H, Zhang J, Gong Y, Martin L, Louis JC, Yan Q, Richards WG, Citron M, Vassar R (2001) Mice deficient in BACE1, the Alzheimer's beta-secretase, have normal phenotype and abolished beta-amyloid generation. Nat Neurosci 4:231232. doi: $10.1038 / 85059$

35. McKenney RJ, Huynh W, Tanenbaum ME, Bhabha G, Vale RD (2014) Activation of cytoplasmic dynein motility by dynactincargo adapter complexes. Science 345:337-341. doi:10.1126/ science. 1254198

36. Moechars D, Lorent K, De Strooper B, Dewachter I, Van Leuven $\mathrm{F}$ (1996) Expression in brain of amyloid precursor protein mutated in the alpha-secretase site causes disturbed behavior, neuronal degeneration and premature death in transgenic mice. EMBO J 15:1265-1274

37. Moughamian AJ, Holzbaur EL (2012) Dynactin is required for transport initiation from the distal axon. Neuron 74:331-343. doi:10.1016/j.neuron.2012.02.025

38. Mullan M, Crawford F, Axelman K, Houlden H, Lilius L, Winblad B, Lannfelt L (1992) A pathogenic mutation for probable Alzheimer's disease in the APP gene at the N-terminus of betaamyloid. Nat Genet 1:345-347

39. O'Connor T, Sadleir KR, Maus E, Velliquette RA, Zhao J, Cole SL, Eimer WA, Hitt B, Bembinster LA, Lammich S, Lichtenthaler SF, Hebert SS, De Strooper B, Haass C, Bennett DA, Vassar R (2008) Phosphorylation of the translation initiation factor eIF2alpha increases BACE1 levels and promotes amyloidogenesis. Neuron 60:988-1009. doi:10.1016/j. neuron.2008.10.047

40. Oakley H, Cole SL, Logan S, Maus E, Shao P, Craft J, GuillozetBongaarts A, Ohno M, Disterhoft J, Van Eldik L, Berry R, Vassar $\mathrm{R}$ (2006) Intraneuronal beta-amyloid aggregates, neurodegeneration, and neuron loss in transgenic mice with five familial Alzheimer's disease mutations: potential factors in amyloid plaque formation. J Neurosci 26:10129-10140

41. Ohno M, Cole SL, Yasvoina M, Zhao J, Citron M, Berry R, Disterhoft JF, Vassar R (2007) BACE1 gene deletion prevents neuron loss and memory deficits in 5XFAD APP/PS1 transgenic mice. Neurobiol Dis 26:134-145. doi:10.1016/j.nbd.2006.12.008

42. Patel AN, Jhamandas JH (2012) Neuronal receptors as targets for the action of amyloid-beta protein (Abeta) in the brain. Expert Rev Mol Med 14:e2. doi:10.1017/S1462399411002134

43. Perlson E, Maday S, Fu MM, Moughamian AJ, Holzbaur EL (2010) Retrograde axonal transport: pathways to cell death? Trends Neurosci 33:335-344. doi:10.1016/j.tins.2010.03.006

44. Poon WW, Blurton-Jones M, Tu CH, Feinberg LM, Chabrier MA, Harris JW, Jeon NL, Cotman CW (2011) Beta-amyloid impairs axonal BDNF retrograde trafficking. Neurobiol Aging 32:821-833. doi:10.1016/j.neurobiolaging.2009.05.012

45. Rajendran L, Honsho M, Zahn TR, Keller P, Geiger KD, Verkade P, Simons K (2006) Alzheimer's disease beta-amyloid peptides are released in association with exosomes. Proc Natl Acad Sci USA 103:11172-11177. doi:10.1073/pnas.0603838103

46. Rajendran L, Schneider A, Schlechtingen G, Weidlich S, Ries J, Braxmeier T, Schwille P, Schulz JB, Schroeder C, Simons M, Jennings G, Knolker HJ, Simons K (2008) Efficient inhibition of the Alzheimer's disease beta-secretase by membrane targeting. Science 320:520-523. doi:10.1126/science.1156609

47. Roberson ED, Scearce-Levie K, Palop JJ, Yan F, Cheng IH, Wu T, Gerstein H, Yu GQ, Mucke L (2007) Reducing endogenous tau ameliorates amyloid beta-induced deficits in an Alzheimer's disease mouse model. Science 316:750-754. doi:10.1126/ science. 1141736

48. Sadleir KR, Eimer WA, Kaufman RJ, Osten P, Vassar R (2014) Genetic inhibition of phosphorylation of the translation initiation factor eIF2alpha does not block Abeta-dependent elevation of BACE1 and APP levels or reduce amyloid pathology in a mouse model of Alzheimer's disease. PLoS One 9:e101643. doi:10.1371/journal.pone.0101643

49. Sadleir KR, Vassar R (2012) Cdk5 protein inhibition and Abeta42 increase BACE1 protein level in primary neurons by a post-transcriptional mechanism: implications of CDK5 as a therapeutic target for Alzheimer disease. J Biol Chem 287:7224 7235. doi:10.1074/jbc.M111.333914

50. Sanchez-Varo R, Trujillo-Estrada L, Sanchez-Mejias E, Torres M, Baglietto-Vargas D, Moreno-Gonzalez I, De Castro V, Jimenez S, Ruano D, Vizuete M, Davila JC, Garcia-Verdugo JM, Jimenez AJ, Vitorica J, Gutierrez A (2012) Abnormal accumulation of autophagic vesicles correlates with axonal and synaptic pathology in young Alzheimer's mice hippocampus. Acta Neuropathol 123:53-70. doi:10.1007/ s00401-011-0896-x

51. Selkoe DJ (1991) The molecular pathology of Alzheimer's disease. Neuron 6:487-498

52. Shi Q, Prior M, He W, Tang X, Hu X, Yan R (2009) Reduced amyloid deposition in mice overexpressing RTN3 is adversely affected by preformed dystrophic neurites. J Neurosci 29:91639173. doi:10.1523/JNEUROSCI.5741-08.2009

53. Shi Q, Prior M, Zhou X, Tang X, He W, Hu X, Yan R (2013) Preventing formation of reticulon 3 immunoreactive dystrophic neurites improves cognitive function in mice. J Neurosci 33:30593066. doi:10.1523/JNEUROSCI.2445-12.2013

54. Sinha S, Anderson JP, Barbour R, Basi GS, Caccavello R, Davis D, Doan M, Dovey HF, Frigon N, Hong J, Jacobson-Croak K, Jewett N, Keim P, Knops J, Lieberburg I, Power M, Tan H, Tatsuno G, Tung J, Schenk D, Seubert P, Suomensaari SM, Wang S, Walker D, Zhao J, McConlogue L, John V (1999) Purification and cloning of amyloid precursor protein beta-secretase from human brain. Nature 402:537-540. doi:10.1038/990114

55. Stine WB Jr, Dahlgren KN, Krafft GA, LaDu MJ (2003) In vitro characterization of conditions for amyloid-beta peptide oligomerization and fibrillogenesis. J Biol Chem 278:11612-11622

56. Sun X, He G, Qing H, Zhou W, Dobie F, Cai F, Staufenbiel M, Huang LE, Song W (2006) Hypoxia facilitates Alzheimer's disease pathogenesis by up-regulating BACE1 gene expression. Proc Natl Acad Sci USA 103:18727-18732

57. Tang Y, Scott DA, Das U, Edland SD, Radomski K, Koo EH, Roy S (2012) Early and selective impairments in axonal transport kinetics of synaptic cargoes induced by soluble amyloid beta-protein oligomers. Traffic 13:681-693. doi:10.1111/j.1600-0854.2012.01340.x

58. Tanzi RE (2012) The genetics of Alzheimer disease. Cold Spring Harb Perspect Med. doi:10.1101/cshperspect.a006296

59. Terry RD, Masliah E, Salmon DP, Butters N, DeTeresa R, Hill R, Hansen LA, Katzman R (1991) Physical basis of cognitive alterations in Alzheimer's disease: synapse loss is the major correlate of cognitive impairment. Ann Neurol 30:572-580. doi:10.1002/ ana.410300410

60. Tesco G, Koh YH, Kang EL, Cameron AN, Das S, Sena-Esteves M, Hiltunen M, Yang SH, Zhong Z, Shen Y, Simpkins JW, Tanzi RE (2007) Depletion of GGA3 stabilizes BACE and enhances beta-secretase activity. Neuron 54:721-737

61. Tong Y, Zhou W, Fung V, Christensen MA, Qing H, Sun X, Song W (2005) Oxidative stress potentiates BACE1 gene expression and Abeta generation. J Neural Transm 112:455-469

62. Tsai J, Grutzendler J, Duff K, Gan WB (2004) Fibrillar amyloid deposition leads to local synaptic abnormalities and breakage of neuronal branches. Nat Neurosci 7:1181-1183. doi:10.1038/ nn 1335

63. Tu S, Okamoto S, Lipton SA, Xu H (2014) Oligomeric Abetainduced synaptic dysfunction in Alzheimer's disease. Mol Neurodegener 9:48. doi:10.1186/1750-1326-9-48 
64. Turner RS, Suzuki N, Chyung AS, Younkin SG, Lee VM (1996) Amyloids beta40 and beta42 are generated intracellularly in cultured human neurons and their secretion increases with maturation. J Biol Chem 271:8966-8970

65. Uryu K, Chen XH, Martinez D, Browne KD, Johnson VE, Graham DI, Lee VM, Trojanowski JQ, Smith DH (2007) Multiple proteins implicated in neurodegenerative diseases accumulate in axons after brain trauma in humans. Exp Neurol 208:185-192

66. Vassar R, Bennett BD, Babu-Khan S, Kahn S, Mendiaz EA, Denis P, Teplow DB, Ross S, Amarante P, Loeloff R, Luo Y, Fisher S, Fuller J, Edenson S, Lile J, Jarosinski MA, Biere AL, Curran E, Burgess T, Louis J-C, Collins F, Treanor J, Rogers G, Citron M (1999) Beta-secretase cleavage of Alzheimer's amyloid precursor protein by the transmembrane aspartic protease BACE. Science 286:735-741

67. Vassar R, Kuhn PH, Haass C, Kennedy ME, Rajendran L, Wong PC, Lichtenthaler SF (2014) Function, therapeutic potential and cell biology of BACE proteases: current status and future prospects. J Neurochem 130:4-28. doi:10.1111/jnc.12715

68. Velliquette RA, O'Connor T, Vassar R (2005) Energy inhibition elevates beta-secretase levels and activity and is potentially amyloidogenic in APP transgenic mice: possible early events in Alzheimer's disease pathogenesis. J Neurosci 25:10874-10883

69. Wang WX, Rajeev BW, Stromberg AJ, Ren N, Tang G, Huang Q, Rigoutsos I, Nelson PT (2008) The expression of microRNA miR-107 decreases early in Alzheimer's disease and may accelerate disease progression through regulation of beta-site amyloid precursor protein-cleaving enzyme 1. J Neurosci 28:1213-1223

70. Wang X, Perry G, Smith MA, Zhu X (2010) Amyloid-betaderived diffusible ligands cause impaired axonal transport of mitochondria in neurons. Neurodegener Dis 7:56-59. doi:10.1159/000283484

71. Wen Y, Onyewuchi O, Yang S, Liu R, Simpkins JW (2004) Increased beta-secretase activity and expression in rats following transient cerebral ischemia. Brain Res 1009:1-8

72. Wen Y, Yu WH, Maloney B, Bailey J, Ma J, Marie I, Maurin T, Wang L, Figueroa H, Herman M, Krishnamurthy P, Liu L, Planel E, Lau LF, Lahiri DK, Duff K (2008) Transcriptional regulation of beta-secretase by $\mathrm{p} 25 / \mathrm{cdk} 5$ leads to enhanced amyloidogenic processing. Neuron 57:680-690

73. Willem M, Tahirovic S, Busche MA, Ovsepian SV, Chafai M, Kootar S, Hornburg D, Evans LD, Moore S, Daria A, Hampel H, Muller V, Giudici C, Nuscher B, Wenninger-Weinzierl A, Kremmer E, Heneka MT, Thal DR, Giedraitis V, Lannfelt L, Muller U, Livesey FJ, Meissner F, Herms J, Konnerth A, Marie H, Haass C (2015) eta-Secretase processing of APP inhibits neuronal activity in the hippocampus. Nature 526:443-447. doi:10.1038/nature14864

74. Wong PC, Marszalek J, Crawford TO, Xu Z, Hsieh ST, Griffin JW, Cleveland DW (1995) Increasing neurofilament subunit NF-M expression reduces axonal NF-H, inhibits radial growth, and results in neurofilamentous accumulation in motor neurons. J Cell Biol 130:1413-1422

75. Wu HY, Hudry E, Hashimoto T, Kuchibhotla K, Rozkalne A, Fan Z, Spires-Jones T, Xie H, Arbel-Ornath M, Grosskreutz CL, Bacskai BJ, Hyman BT (2010) Amyloid beta induces the morphological neurodegenerative triad of spine loss, dendritic simplification, and neuritic dystrophies through calcineurin activation. J Neurosci 30:2636-2649. doi:10.1523/ JNEUROSCI.4456-09.2010

76. Xia W, Yang T, Shankar G, Smith IM, Shen Y, Walsh DM, Selkoe DJ (2009) A specific enzyme-linked immunosorbent assay for measuring beta-amyloid protein oligomers in human plasma and brain tissue of patients with Alzheimer disease. Arch Neurol 66:190-199. doi:10.1001/archneurol.2008.565

77. Xie H, Guan J, Borrelli LA, Xu J, Serrano-Pozo A, Bacskai BJ (2013) Mitochondrial alterations near amyloid plaques in an Alzheimer's disease mouse model. J Neurosci 33:17042-17051. doi:10.1523/JNEUROSCI.1836-13.2013

78. Xie H, Hou S, Jiang J, Sekutowicz M, Kelly J, Bacskai BJ (2013) Rapid cell death is preceded by amyloid plaque-mediated oxidative stress. Proc Natl Acad Sci USA 110:7904-7909. doi:10.1073/pnas.1217938110

79. Yan R, Bienkowski MJ, Shuck ME, Miao H, Tory MC, Pauley AM, Brashier JR, Stratman NC, Mathews WR, Buhl AE, Carter DB, Tomasselli AG, Parodi LA, Heinrikson RL, Gurney ME (1999) Membrane-anchored aspartyl protease with Alzheimer's disease beta-secretase activity. Nature 402:533-537. doi:10.1038/990107

80. Yang LB, Lindholm K, Yan R, Citron M, Xia W, Yang XL, Beach T, Sue L, Wong P, Price D, Li R, Shen Y (2003) Elevated betasecretase expression and enzymatic activity detected in sporadic Alzheimer disease. Nat Med 9:3-4. doi:10.1038/nm0103-3

81. Yu WH, Cuervo AM, Kumar A, Peterhoff CM, Schmidt SD, Lee JH, Mohan PS, Mercken M, Farmery MR, Tjernberg LO, Jiang Y, Duff K, Uchiyama Y, Naslund J, Mathews PM, Cataldo AM, Nixon RA (2005) Macroautophagy - a novel Beta-amyloid peptide-generating pathway activated in Alzheimer's disease. J Cell Biol 171:87-98. doi:10.1083/jcb.200505082

82. Zempel H, Luedtke J, Kumar Y, Biernat J, Dawson H, Mandelkow E, Mandelkow EM (2013) Amyloid-beta oligomers induce synaptic damage via Tau-dependent microtubule severing by TTLL6 and spastin. EMBO J 32:2920-2937. doi:10.1038/ emboj. 2013.207

83. Zetterberg H, Blennow K (2013) Biomarker evidence for uncoupling of amyloid build-up and toxicity in Alzheimer's disease. Alzheimers Dement 9:459-462. doi:10.1016/j.jalz.2012.07.002

84. Zhang X, Zhou K, Wang R, Cui J, Lipton SA, Liao FF, Xu H, Zhang YW (2007) Hypoxia-inducible factor 1alpha (HIF1alpha)-mediated hypoxia increases BACE1 expression and beta-amyloid generation. J Biol Chem 282:10873-10880

85. Zhang XM, Cai Y, Xiong K, Cai H, Luo XG, Feng JC, Clough RW, Struble RG, Patrylo PR, Yan XX (2009) Beta-secretase-1 elevation in transgenic mouse models of Alzheimer's disease is associated with synaptic/axonal pathology and amyloidogenesis: implications for neuritic plaque development. Eur $\mathbf{J}$ Neurosci 30:2271-2283. doi:10.1111/j.1460-9568.2009.07017.x

86. Zhao J, Fu Y, Yasvoina M, Shao P, Hitt B, O'Connor T, Logan S, Maus E, Citron M, Berry R, Binder L, Vassar R (2007) Betasite amyloid precursor protein cleaving enzyme 1 levels become elevated in neurons around amyloid plaques: implications for Alzheimer's disease pathogenesis. J Neurosci 27:3639-3649

87. Zhou L, Brouwers N, Benilova I, Vandersteen A, Mercken M, Van Laere K, Van Damme P, Demedts D, Van Leuven F, Sleegers $\mathrm{K}$, Broersen K, Van Broeckhoven C, Vandenberghe R, De Strooper B (2011) Amyloid precursor protein mutation E682K at the alternative beta-secretase cleavage beta'-site increases Abeta generation. EMBO Mol Med 3:291-302. doi:10.1002/ emmm.201100138

88. Zong Y, Wang H, Dong W, Quan X, Zhu H, Xu Y, Huang L, Ma C, Qin C (2011) miR-29c regulates BACE1 protein expression. Brain Res 1395:108-115 